The research program of the Center for Economic Studies (CES) produces a wide range of theoretical and empirical economic analyses that serve to improve the statistical programs of the U.S. Bureau of the Census. Many of these analyses take the form of CES research papers. The papers are intended to make the results of CES research available to economists and other interested parties in order to encourage discussion and obtain suggestions for revision before publication. The papers are unofficial and have not undergone the review accorded official census Bureau publications. The opinions and conclusions expressed in the papers are those of the authors and do not necessarily represent those of the U.S. Bureau of the Census. Republication in whole or part must be cleared with the authors.

\title{
IT AND BEYOND: THE CONTRIBUTION OF HETEROGENOUS CAPITAL TO PRODUCTIVITY
}

\author{
by \\ Daniel Wilson * \\ Federal Reserve Bank of San Francisco
}

CES 04-20 December, 2004

All papers are screened to ensure that they do not disclose confidential information. Persons who wish to obtain a copy of the paper, submit comments about the paper, or obtain general information about the series should contact Sang $V$. Nguyen, Editor, Discussion Papers, Center for Economic Studies, Washington Plaza II, Room 206, Bureau of the Census, Washington, DC 20233-6300, (301-763-1882) or INTERNET address snguyen@ces.census.gov. 


\title{
IT and Beyond: The Contribution of Heterogeneous Capital to Productivity ${ }^{1}$
}

\author{
Daniel J. Wilson
}

Draft: September 2004

\footnotetext{
${ }^{1}$ Economist, Federal Reserve Bank of San Francisco, 101 Market St., MS 1130, San Francisco, CA 94105; (415) 974-3423 (office), (415) 974-2168 (fax); Daniel.Wilson@sf.frb.org (email). Geoffrey MacDonald provided superb research assistance. I thank Ron Jarmin and Kristen McCue of the Center for Economic Studies for providing the ACES-Compustat bridge file and Larry Rosenblum for providing the data on BLS rental prices. This paper benefitted from helpful comments from Kevin Stiroh, Bart Hobijn, John Haltiwanger, Sandy Black, Erik Brynjolfsson, Bronwyn Hall, and seminar participants at FRBSF, CES, UC Berkeley, and the NBER Summer Institute. The research in this paper was conducted while the author was a research associate at the CES and California Census Research Data Center (CCRDC); special thanks go to Ritch Milby of the CCRDC. Research results and conclusions expressed are those of the author and do not necessarily indicate concurrence by the Bureau of the Census, the CES, or the Federal Reserve System. This paper has been screened to ensure that no confidential data are revealed.
} 


\begin{abstract}
This paper explores the relationship between capital composition and productivity using a unique and remarkably detailed data set on firm-level, asset-specific investment in the U.S. Using cross-sectional and longitudinal regressions, I find that among all types of capital, only computers, communications equipment, software, and office building are associated (positively) with current and subsequent years' multifactor productivity. The link between offices and productivity, however, is shown to be due to the correlation between the use of offices and organizational capital. In contrast, the link between ICT equipment and productivity is robust to a number of controls and appears to be part causal effect and part reflection of the correlation between ICT and firm fixed (or slow-moving) effects. The implied marginal products by capital type are derived and compared to official data on rental prices; substantial differences exist for a number of key capital types. Lastly, I provide evidence of complementaries and substitutabilities among capital types - a rejection of the common assumption of perfect substitutability - and between particular capital types and labor. [Keywords: Capital Heterogeneity, Productivity, Investment, Production Function Estimation; JEL Codes D21, D24, D29.]
\end{abstract}




\section{Introduction}

There has been a tremendous amount of public interest and debate in the last several years on how information and communication technologies (IT) affect productivity. This leads one to wonder: Is ICT special? That is, does investment in ICT equipment have a greater impact on productivity than investment in other capital goods? More generally, does the mix of physical capital affect total factor productivity (TFP) (as it is conventionally measured), and if so, how?

Understanding how ICT interacts with other capital goods in production is of fundamental importance to understanding the nature of the production function. It is also particularly relevant for understanding the sources of the rapid rise in aggregate TFP over the last decade, a period in which the mix of physical capital in the economy has changed dramatically.

Beyond the specific issue of the ICT-productivity link, previous research has not empirically examined the relationship between the entire capital mix and productivity. This paper, however, is the first productivity study to make use of the micro-level data from a unique, highly detailed survey of U.S. businesses, the 1998 Annual Capital Expenditures Survey (ACES) and is able to address this and other important questions related to heterogeneous capital investment and productivity.

The special focus on IT up to now is understandable given its increasingly vital role in business and personal activity. However, there are several reasons to expand our attention beyond the productivity impact of IT to the impact of other capital goods as well, and, in fact, to expand our attention to the impact of the capital mix more generally. First, computers and communications equipment are not purchased in isolation. They are often purchased in conjunction with other capital goods to build a system of capital to accomplish productivity enhancements. Wilson [2004], in fact, using the full 1998 ACES sample of nearly 30,000 firms, provides evidence of exactly that. ${ }^{1}$ Thus, even if our interest is only in the productivity impact of IT, we must account for its correlation with other capital goods that have their own impact on productivity.

Second, given that in practice firms typically have budget constraints on total capital expenditures, policy prescriptions calling for increased investment in IT are

\footnotetext{
${ }^{1}$ Specifically, Wilson [2004] finds that the share of Computers in total firm investment is positively correlated with the investment shares of Other Office Equipment, Software, Furniture, Office Buildings, Commercial Buildings, and several other types of capital.
} 
of little practical value without prescriptions as to what type(s) of capital should be replaced. For this purpose, one must know the productivity impacts of every type of capital. Third, nearly all micro-level production studies assume a single, homogenous capital stock (two at most). In reality, capital is clearly heterogeneous. In fact, even the standard Neoclassical model, which assumes perfect substitutability among capital goods, calls for capital heterogeneity to be taken into account. ${ }^{2}$ If one goes even further by allowing imperfect substitutability, then one confers unto the capital mix an even greater role in determining productivity.

The goal of this paper is to begin to fill in this gap in our understanding of the relationship between capital mix and produtivity. Combining new data on assetspecific investment with data from financial records for publicly-traded firms enables us address this issue in a comprehensive manner. The recent Annual Capital Expenditures Survey (ACES) of 1998, conducted by the U.S. Census Bureau, is a unique data set containing investment by 55 separate types of capital for a representative sample of roughly 30,000 businesses spanning the U.S. private nonfarm economy. The ACES does not, however, collect information on other factor inputs such as labor. By matching the publicly-traded ACES companies to the Compustat research file, I am able to observe not only these firms' quantities of factor inputs in 1998, but also the quantities of factor inputs and output in other years as well. Thus, I can explore the cross-sectional and, to some extent, longitudinal relationship between capital mix and productivity.

Most previous micro production studies, especially those focusing on IT capital, have been restricted to the manufacturing sector. ${ }^{3}$ Thus, not only does this paper move the literature forward in terms of the focus on heterogeneous capital, it also moves it forward by offering results based on a much broader coverage of the economy (as well

\footnotetext{
${ }^{2}$ In the standard (Jorgensonian) Neoclassical model, different capital goods are assumed to have different marginal products (and user costs) which depend on depreciation rates, tax considerations, and expected price appreciation, as shown in the seminal work of Hall and Jorgenson [1967]. The capital service flow from an individual capital good is the product of its capital stock and its user cost. Total capital services is then a function (e.g., a sum) of the individual capital services. (See Jorgenson and Stiroh [2000]). Unfortunately, micro-level data typically do not provide information on individual capital stocks and thus micro-level production studies typically omit capital mix which, even under this Neoclassical model, should affect both output and conventionally-measured TFP.

${ }^{3}$ Notable exceptions are Doms, Jarmin, and Klimek's [2002] study of retail trade, Hubbard's [2004] study of the trucking industry, and Greenan and Mairesse's [2000] analysis of French services (in addition to manufacturing).
} 
as offering results separately for manufacturing and nonmanufacturing). ${ }^{4}$ It should also be noted that this paper covers a time period, 1998-2001, far more recent than most other contemporaneous studies. ${ }^{5}$

I first estimate the effect of each capital type's share of investment on conventionallymeasured TFP in the current and subsequent years. TFP here is a productivity residual, obtained in three alternative ways (all based on a standard Cobb-Douglas production function): (1) a production function regression, (2) a labor productivity regression, and (3) an index of multi-factor productivity constructed using factor shares. ${ }^{6}$ Exploiting the fact that I have data for years prior to the 1998 investment decision as well as after, I assess the extent to which firm fixed, or slow-moving, effects such as workplace practices or organizational capital may be responsible for any links between productivity and particular types of investment. ${ }^{7}$ Third, in order to address the issue of complementarities and substitutabilities among capital goods, I estimate the effects on productivity of combining different pairs of capital types together. Lastly, I estimate whether capital types differ in terms of their complementarity or substitutablity with labor - i.e., which capital types are labor-saving or labor-augmenting relative to other capital types.

The regression results clearly indicate that the use of computers, communications equipment, software, and offices are positively associated with current and subsequent years' total factor productivity. I perform a number of exercises to determine the primary direction of causality explaining these correlations. I find the results are robust to including either future TFP (i.e., one-year lead of measured TFP using factor cost shares) or a polynomial of investment, capital, and age (a la Ol-

\footnotetext{
${ }^{4}$ As pointed out by Brynjolfsson and Hitt [1996]: "A convincing assessment of [Information Spending] productivity would ideally employ a sample which included a large share of the economy..., but at a level of detail that disaggregated inputs and outputs for individual firms...."

${ }^{5}$ For example, Gilchrist, et al. [2003] explore the 1986-93 period; Brynjolfsson and Hitt [2003] covers 1987-94; Black \& Lynch [2001] covers 1987-93; and Lehr \& Lichtenberg [1999] covers 1977-93.

${ }^{6}$ This paper focuses on the effect of capital mix on conventionally-measured TFP, which is output net of the contributions of labor and the total capital stock. True TFP, on the other-hand, arguably should be net of any contribution from the composition (and quality) of capital as well. In terms of the model in Section 3, the variable $A$ would capture true TFP, whereas conventionally-measured TFP is $A\left[1+\sum_{p=1}^{N}\left(\theta_{p} \xi_{p}\right)\right]^{\alpha}$.

${ }^{7}$ See Black and Lynch [2001]; Brynjolfsson, Hitt, and Yang [2002]; and Bresnahan, Brynjolfsson, and Hitt [2001] for evidence on the complementarity of IT with workplace practices, organizational capital, and other elements of intangible capital.
} 
ley and Pakes [1996]) in the regressions - both techniques for directly controlling for unobserved "transmitted" productivity components. However, including a proxy for organizational capital wipes out the offices-productivity association, suggesting offices are strongly correlated with organizational capital, while leaving computers, communication equipment, and software with statistically significant link with productivity. Furthermore, the data suggest that investment in offices may actually be caused, or at least preceded, by total factor productivity.

Using the results of the production function regressions, I show that one can back out the implied marginal products for each capital type from these regression coefficients by combining them with official (BLS) data on depreciation rates. These marginal products can then be compared to the rental prices by capital type provided by the BLS. For the most part, the implied marginal products are strikingly similar to these rental price estimates. However, for a few key types like computers, communications equipment, and software, the implied marginal products are found to be substantially higher than the official rental prices.

I also find evidence that the "bundling" of certain capital goods has an effect on total factor productivity. In fact, using any reasonable division of types into "hightech" and "low-tech" categories, the data indicates that high-tech capital goods tend to be complementary with low-tech capital goods and substitutable with other high-tech capital. Not only does this result have interesting implications for productivity, it also is a rejection of the assumption that capital goods are perfectly substitutable, which is common in the productivity literature.

In addition to complementarities and substitubilities among capital types, I find complementarities and substitubilities between certain capital types and labor. In particular, software is found to be especially labor-saving, while General Purpose Machinery and Trucks are especially labor-augmenting. Given the well-documented shifts in aggregate capital composition in the U.S. over the last decade or so, this result may have implications for trends in labor demand and relative wages.

These results show that the common empirical practice of assuming perfect substitutability and ignoring variation in capital mix can lead to very misleading results. They also show that ICT capital is not alone in having a positive association with productivity, though it is special in that only ICT's association appears to be causal and robust to controlling for organization capital. Finally, the results suggest that official (BLS) estimates of rental prices by capital good, which are used in constructing 
the macro and industry data used in growth accounting studies, may be too low for ICT capital goods.

\section{Background}

As mentioned at the start of the paper, up to this point the literature on the productivity impact of disaggregate investment has focused almost exclusively on computers and communications equipment (and mostly just computers). ${ }^{8}$ The macroeconomic literature has typically relied on growth accounting exercises to explore the issue, while microeconomic studies have generally relied on firm- or establishment-level production function estimation, with IT capital as a separate production input in addition to labor and non-IT capital. ${ }^{9}$

During the 1980s and the first half of the 1990s, most studies found little or no evidence of an economically important contribution of ICT to productivity or productivity growth. Examples include Oliner and Sichel [1994], Griliches and Siegel [1992], and Berndt and Morrison [1995]. Berndt and Morrison [1995], in fact, found that ICT capital's share of total capital services was negatively related to TFP in panel fixed-effects regressions using data on 2-digit manufacturing industries from 1968-1986.

More recently, a consensus appears to be forming that IT investment is positively associated with total factor productivity, although the magnitude, direction of causality, and timing of this impact is still very much under debate. ${ }^{10}$ Oliner and Sichel [2000] used growth accounting techniques to identify the contribution, within a standard Neoclassical production framework, of ICT capital to aggregate productivity growth. They find that the use and production of ICT equipment together account for

\footnotetext{
${ }^{8}$ A possible exception is Caselli and Wilson [2004], which used country-level data on capital imports to explore the determinants of capital composition and its effects on income per capita. To the extent that income per capita reflects total factor productivity and capital imports reflect investment, their study does address the issue of how capital mix affects productivity.

${ }^{9}$ On the macro side, see Oliner and Sichel [1994, 2000], Jorgenson and Stiroh [2000], and Gordon [2000]. On the micro side, see Brynjolfsson and Hitt [1996, 2003]; Lehr and Lichtenberg [1999]; Greenan and Mairesse [2000]; and Gilchrist, Gurbuxani, and Town [2003]. For similar analyses at the industry-level, see Berndt and Morrison [1995]; Gera, Gu, and Lee [1999]; and Stiroh [2002].

${ }^{10}$ The issues of this debate are discussed in Stiroh [2003], which performs a meta-analysis of the literature on estimating the elasticity of output with respect to IT capital. He shows that estimates of this elasticity are sensitive to the time period and industry coverage of the data, the model specification, and the econometric technique.
} 
two-thirds of the acceleration in productivity growth that occurred between the first half and the second half of the 1990s.

On the micro side, Brynjolfsson and Hitt [1995, 1996] estimate that the returns to IT spending are substantially higher than those to non-IT spending. Greenan and Mairesse [2000] find evidence that computer use has a positive impact on productivity at the firm level using data on the French manufacturing and services sectors. However, they cannot reject the hypothesis that computer's contribution to productivity is the same as the contribution of other capital. Gilchrist, Gurbaxani, and Town [2003] use a modified version of the Arellano and Bond [1991] GMM estimator to estimate the elasticity of the IT capital stock via both a production function and a TFP framework. They find that IT's elasticity in the production function is about equal to its cost share and is not significant in the TFP regression (both consistent with normal returns within the Neoclassical model). However, they also find that personal computers (PCs) have an impact on productivity above and beyond their contribution to the IT stock. They find this is driven by the durable goods sector; PCs have no impact in the nondurables sector. Brynjolfsson and Hitt [2003] estimate the elasticity of computers using both short- and long-difference regressions. They find that computers' elasticity is consistent with their cost share in the short differences; but, consistent with Gilchrist, et al., the long difference results suggest that the elasticity is significantly higher than computers' cost share.

While these and other studies in the productivity literature up to this point has generally focused exclusively on computers (and, to a lesser extent, communications equipment), the investment literature has explored the implications of capital heterogeneity for adjustment costs (e.g., Chirinko [1993]) and tax policy (Goolsbee [2004]; Cummins, Hassett, and Hubbard [1994]). Most relevant to this paper, Cummins and Dey [1998] estimate a structural model in which heterogeneous capital goods are allowed to differentially affect the production and adjustment technologies and find important effects of imperfect substitutability. Their capital stock data, however, is only broken down into two groups: equipment and structures.

\section{Model}

The focus of this paper is on the relationship between capital mix and productivity at the firm level. In the typical Neoclassical production framework, once the service 
flow of total capital is accounted for, capital mix plays no role in determining output. Consider the standard Cobb-Douglas (ex-post) production function in capital services $(J)$ and labor $(L)$ with a Hicks-neutral technology shift parameter (subscripts for time and firm are omitted to economize on notation): $Y=A J^{\alpha} L^{\beta}$. Assuming the necessary and sufficient conditions for the existence of a single aggregate $J$ hold (see Solow [19551956] and Fisher [1965]), $J$ can be considered the weighted sum of disaggregate (real) capital stocks - stocks differentiated either by type or by vintage (here by type). ${ }^{11}$ The production function can then be written as follows:

$$
\begin{aligned}
Y & =A\left[\sum_{p=0}^{N}\left[\left(1+\theta_{p}\right) K_{p}\right]\right]^{\alpha} L^{\beta} ; \theta_{0}=0 \\
& =A\left[1+\sum_{p=1}^{N}\left(\theta_{p} \xi_{p}\right)\right]^{\alpha} K^{\alpha} L^{\beta}
\end{aligned}
$$

where $K=\sum_{p=0}^{N} K_{p}$ and $\xi_{p}=K_{p} / K ; p$ indexes capital types: $p=0,1, \ldots, N-1$, where $N$ is the number of types. Each $K_{p}$ is measured in physical units, or equivalently, by the constant dollar value of capital. The weights, $\left(1+\theta_{p}\right)$, convert the dollar value of capital of type $p$ to quality units that can be compared across types; the quality of $K_{0}$ is used as the numeraire. $K$ is the total (constant-dollar) value of capital.

Capital type $p$ 's relative marginal product is:

$$
\frac{\partial Y}{\partial K_{p}} / \frac{\partial Y}{\partial K_{0}} \equiv F_{p} / F_{0}=1+\theta_{p} .
$$

Thus, $\theta_{p}$ represents the percentage difference between capital type $p$ 's marginal product and the marginal product of the numeraire capital type. In the standard

\footnotetext{
${ }^{11}$ Solow [1955] established that a necessary and sufficient condition for the existence of a single capital aggregate, $K=g\left(K_{1}, K_{2}\right)$, is that the marginal rate of substitution between different capital types is independent of the quantity of labor (i.e., the heterogeneous capital types must be weakly separable). In addition, Fisher [1965] demonstrated that if different types (or vintages) of capital embody different levels of quality/technology, then there is an additional necessary and sufficient condition for the existence of a single capital aggregate: the heterogeneous quality must be expressible in homogenous constant-quality units - this is the well-known "better = more" assumption. Taken together, these two conditions are equivalent to requiring that different capital types be perfect substitutes once they are properly expressed in constant-quality units. For the majority of the paper (until Section 7), I assume these conditions hold although I do not make the further assumption that ex-post marginal products per dollar of investment are equal across capital subaggregates.
} 
Neoclassical model, optimizing firms choose the quantity of each input such that its marginal product is equal to its price. (In this case, the input is said to be earning normal returns). The ratio between the marginal products of different capital stocks is therefore equal to the ratio of their user costs (see Jorgenson [1963]). Thus, the Neoclassical model would predict that $1+\theta_{p}=\left(c_{p} / c_{0}\right)$, where $c_{p}$ and $c_{0}$ are the user costs for type- $p$ and type- 0 capital, respectively. However, there are a number of possible reasons for $1+\theta_{p} \neq\left(c_{p} / c_{0}\right)$. First, there could be adjustment costs and/or learning-by-doing processes that differentially affect capital goods. Second, there may be unobserved organizational co-investments associated with particular capital goods (though this is something we can partially control for). Third, due to uncertainty regarding the rate of return on capital investments, there could be systematic expectational errors by firms that may be more severe for certain capital goods.

Notice that in the above framework, different capital types are perfectly substitutable (once their quality has been accounted for by $\theta_{p}$ ). In section 7 , I relax this assumption by allowing capital goods to be complementary or substitutable with other capital goods. In other words, I allow the marginal product of capital type $p$ to depend on the quantity of each and every other capital type.

The principal focus of the following section is on obtaining consistent estimates of the sequence of $\theta_{p} \mathrm{~s}\left(\left\{\theta_{p}\right\}_{p=1}^{N}\right)$, i.e., the coefficients on the capital shares. To estimate the $\theta_{p} \mathrm{~s}$ via linear regression, the production function must first be linearized. If $\sum_{p=1} \theta_{p} \xi_{p} \approx 0$, then, to an approximation, the production function in logs (lowercase letters denote logs) becomes ${ }^{12}$ :

$$
y=a+\alpha\left[\theta_{1} \xi_{1}+\ldots+\theta_{N} \xi_{N}\right]+\alpha k+\beta \ell
$$

At least three regression specifications allowing for the estimation of $\left\{\theta_{p}\right\}$ can

\footnotetext{
${ }^{12}$ Any approximation error introduced here is likely to result in a negative bias in OLS estimation of the $\theta_{p}$ s. For simplicity, consider the case where there is only one capital type $(p=1)$ in addition to the numeraire type. As $\theta_{1} \xi_{1}$ diverges from zero, the approximation error, $\log \left(1+\theta_{1} \xi_{1}\right)-\theta_{1} \xi_{1}$, which is an omitted variable in the estimation, will become increasingly negative. So if the true $\theta_{1}$ is nonzero, then the omitted variable will be more negative for firms with larger shares of investment in type $1\left(\xi_{1}\right)$. Hence, there will be a negative bias on the estimator of $\theta_{1}$. In particular, notice that any findings of excess returns that we obtain are likely to be underestimates whereas findings of below-normal returns may be overstated.
} 
be derived from (3). ${ }^{13} \quad$ First, adding an i.i.d. disturbance term, equation (3) forms a regression equation from which one can estimate the parameters $a, \alpha, \beta$, and $\left\{\theta_{p}\right\}$. Second, the production function specification can be converted into a labor productivity specification by subtracting $\ell$ from both sides of (3). ${ }^{14}$ Third, assuming constant returns to scale and perfect competition, one can measure $\alpha$ and $\beta$ using capital and labor's income shares $(\tilde{\alpha}$ and $\tilde{\beta})$, respectively, and subtract $(\tilde{\alpha} k+\tilde{\beta} \ell)$ from both sides of (3) in order to obtain a measure of $(\log )$ multi-factor productivity (here, 2-factor productivity, (2FP)):

$$
\begin{gathered}
2 f p=y-(\tilde{\alpha} k+\tilde{\beta} \ell), \\
\text { where } \tilde{\beta}=w L / p Y \text { and } \tilde{\alpha}=r K / p Y=1-\tilde{\beta} .
\end{gathered}
$$

Here $w, r$, and $p$ are the prices of labor, capital, and output, respectively. The 2fp specification is then:

$$
2 f p=a+\alpha\left[\theta_{1} \xi_{1}+\ldots+\theta_{N} \xi_{N}\right]+\epsilon
$$

where $\epsilon$ is an i.i.d. disturbance term.

Notice that in each of these specifications, the regression coefficient on $\xi_{p}$ actually represents $\alpha \theta_{p}$, not $\theta_{p}$. One must divide the estimated coefficient on $\xi_{p}$ by an estimate of the total capital elasticity in order to back out $\theta_{p}$.

One important aspect of the ACES investment data should be emphasized here. The 1998 ACES provides data on investment by asset type, but not capital stock by asset type (and there are no prior years of disaggregate data with which to build stocks). One would prefer, of course, to have the latter given that theory suggests a relationship between capital composition and productivity, not investment composition (beyond its contribution to capital composition) and productivity. However, as discussed in Section 3, given data on depreciation rates, one can still properly obtain the marginal

\footnotetext{
${ }^{13} \mathrm{~A}$ similar formulation, containing disaggregate capital shares in addition to total capital, was employed in the empirical studies of Berndt and Morrison [1995] and Lehr and Lichtenberg [1999], though to a much more limited extent. The former disaggregated capital into office equipment, other equipment, and structures; the latter broke capital into IT and non-IT capital.

${ }^{14}$ In the labor productivity regressions for which I report results below, I assume constant returns to scale so that labor can be excluded as a regressor.
} 
products implied by the investment share coefficients as long as firms are, on average, approximately near steady-state.

An important limitation of the 1998 ACES data is that it provides data on investment by asset type, but not capital stock by asset type (and there are no prior years of disaggregate data with which to build stocks). Hence, capital shares (the $\xi_{p} \mathrm{~s}$ ) are unobserved. Investment shares, however, are not; and with the proper data, capital shares can be approximated from investment shares. From the standard perpetual inventory equations, $I_{p t}^{i}=\triangle K_{p t}^{i}+\delta_{p} K_{p, t-1}^{i}$ and $I_{t}^{i}=\triangle K_{t}^{i}+\delta K_{t-1}^{i}$, one gets:

$$
\frac{K_{p, t-1}^{i}}{K_{t-1}^{i}}=\frac{\left(g_{t}^{i}+\delta\right)}{\left(g_{p t}^{i}+\delta_{p}\right)} \cdot \frac{I_{p t}^{i}}{I_{t}^{i}}
$$

where $g_{p t}^{i}=\triangle K_{p t}^{i} / K_{p, t-1}^{i}$ and $g_{t}^{i}=\triangle K_{t}^{i} / K_{t-1}^{i}$ are the growth rates of capital type $p$ and total capital, respectively. Unfortunately, $g_{p t}^{i}$ is unobserved in our data. If $g_{t}^{i}$ and $g_{p t}^{i}$ are small (relative to the depreciation rates), as would be expected in a steady state, the first term in the product above is approximately equal to the ratio of total depreciation to type- $p$ depreciation. ${ }^{1516}$ Above, I showed that $\theta_{p}$ represents the relative marginal product of type- $p$ capital (minus one). Using investment shares in lieu of capital shares in our regressions thus changes the interpretation of $\theta_{p}$ from $\left[\left(F_{p} / F_{0}\right)-1\right]$ (eq. $\left.(2)\right)$ to $\left[\left(F_{p} / F_{0}\right)-1\right]\left(\delta / \delta_{p}\right)$. Likewise, I showed above that the Neoclassical prior (based on firms setting factor quantities until marginal products equal factor prices) for this parameter is $\left(c_{p} / c_{0}\right)-1$. Using investment shares, this prior becomes $\left[\left(c_{p} / c_{0}\right)-1\right]\left(\delta / \delta_{p}\right)$. In section 5.3 , I back out the marginal products implied by the estimated $\theta_{p} \mathrm{~s}$ and compare them to the widely-used user cost estimates generated by the Bureau of Labor Statistics (BLS).

Returning to the specifications discussed above, the shift variable $a=\log (A)$ is

\footnotetext{
${ }^{15}$ Lehr and Lichtenberg [1999], in their study of the returns to computer capital, similarly approximated capital shares using the product of investment shares and this ratio of depreciation rates.

${ }^{16}$ To the extent that firms deviate from balanced growth, the bias (on the estimator of $\theta$ ) caused by omitting the difference between the capital share and the investment share in a regression is likely to be negative. The reasoning goes as follows: Since type-specific investment is likely to be lumpy over time, i.e., a high (conditional on industry and other regressors) type- $p$ investment share this period generally signals a low beginning-of-period type- $p$ capital stock share. Thus, the partial correlation between $I_{p}^{i} / I^{i}$ and the omitted variable $\left(K_{p}^{i} / K^{i}-I_{p}^{i} / I^{i}\right)$ is negative, which implies a negative bias on the estimator of the investment share's coefficient $\left(\alpha \theta_{p}\right)$. In particular, significantly positive estimates of $\alpha \theta_{p}$, such as those we obtain for Computers, Software, and Communications Equipment, cannot be explained by omitted variable bias.
} 
an unobserved variable that is likely to vary by firm and may possibly be correlated with the other regressors. To formalize this possibility let us rewrite $a$ as:

$$
a_{i t}=f_{i}+\omega_{i t}+v_{i t} .
$$

The first term, $f_{i}$, is a firm fixed effect. The second term, $\omega_{i t}$, is a productivity shock that is known ("transmitted") to the firm when it makes its input decisions but is unobserved to the econometrician. The third term is the productivity innovation that is ex-ante unknown even to the firm. It is this third term that one might call the "true" productivity innovation. It is orthogonal to all factor inputs including the capital mix. The concern regarding the regressions described above is that both $f_{i}$ and $\omega_{i t}$ may be correlated with firm's investment decisions, including the capital composition decision, leading the OLS estimators of our parameters to be biased.

As for the fixed effect, $f_{i}$, often one can control for it through panel data methods (e.g., first-differencing). In this paper, however, I have only a single cross-section of data (1998) on $\left\{\xi_{p}\right\}$, though I do have panel data for the variables $y, k$, and $\ell$ (below I discuss an alternative exercise which makes use of this panel data, though not to identify $\left.\left\{\theta_{p}\right\}\right)$. Due to this limitation of the data, the primary identification strategy is to focus on the cross-sectional estimation and include as many potential correlates with unobserved contributors to productivity (i.e., with $f_{i}$ and $\omega_{i t}$ ) as possible.

First, I include a number of variables measuring permanent firm characteristics. These consist of 3-digit SIC level industry dummy variables, state dummies, and a 5category indicator of firm size (employment); this size variable is described in Appendix A. The state (of headquarters) dummy is included because a number of studies have found that location has an important effect on firm performance; this effect can be due, for example, to networks/technological spillovers or density (see Audretsch \& Feldman [1996], Ellison \& Glaeser [1997, 1999], Audretch \& Dohse [2004], Hall \& Ciccone [1996]). Second, we include a dummy variable indicating whether or not the firm had an investment spike (defined as investment $20 \%$ or more of the beginning-ofyear book value of capital).

As discussed in Section 6, I also experiment with two more direct approaches to controlling for the unobserved, transmitted productivity component. The first is the Olley and Pakes [1996] approach of proxying for the shock with a polynomial function of (total) investment, capital, and age. The second approach is to include a measure of one-year-ahead MFP (specifically, $2 f p_{t+1}$ ) as an additional regressor. Both of these 
approaches are discussed in more detail in Section 6. In both cases, the estimated coefficients on the investment shares are virtually unchanged relative to the baseline results.

One issue that must be addressed before proceeding is the appropriate measure of output $(Y)$. Typically, one assumes that real value added is produced using capital and labor, as in $Y=A K^{\alpha} L^{\beta}$. However, properly measuring real value added can be quite difficult, especially at the micro level. The most common measure is doubledeflated value added, which is deflated gross output ( $\approx$ sales) minus deflated materials. Separate deflators for materials costs are generally unavailable. Moreover, even if they were, double-deflated value added has been shown to be a biased measure of real value added in the presence of imperfect competition (see Basu \& Fernald [1996]).

In light of these problems with value added as a measure of output, I opt instead to use gross output. Since gross output is a function of materials, as well as capital and labor, one must decide on how materials enter into the production function. One option is to have materials as an additional factor in the Cobb-Douglas production function:

$$
Y=A K^{\alpha} L^{\beta} M^{\gamma}
$$

In practice, though, materials tend to dominate the explanatory power of capital and labor in micro-level estimation, making it difficult to identify the coefficients on capital and labor. Moreover, including materials would limit our sample size considerably since Compustat does not report materials costs for many companies. Another option is to assume that value added $\left(A K^{\alpha} L^{\beta}\right)$ and materials have a Leontief relationship and therefore materials can be excluded from the gross output production function (this is an approach often followed in the micro production estimation literature ${ }^{17}$ ). I follow the latter approach for the most part in this paper. As a robustness check, however, I also report results based on a regression specification derived from equation (7) (see Section 5.4 below).

\footnotetext{
${ }^{17}$ See, e.g., Bahk and Gort [1993].
} 


\section{Data}

\subsection{The Regression Sample}

The principal sources of data for this paper are the 1998 Annual Capital Expenditures Survey (ACES) and Compustat. ${ }^{18}$ The ACES is conducted annually by the U.S. Census Bureau to elicit information on capital expenditures by U.S. private, nonfarm companies. This information is used by the BEA in constructing the National Income and Product Accounts (NIPA). ${ }^{19}$

In typical years, the ACES queries companies on their expenditures on total equipment and total structures, in addition to related values such as book value of capital assets, accumulated depreciation, retirements, etc.. In the 1998 survey, however, the ACES additionally required firms to report their investment broken down by 55 separate types of capital - 26 types of equipment and 29 types of structures. A list of these types is given in Table 1. The 1998 ACES is unique as the only large-scale micro-level U.S. survey of investment that disaggregates investment into a full range of detailed asset types (i.e., beyond simply total equipment and total structures, and beyond just one or two asset types such as computers or transportation equipment). These data on disaggregate investment allow us to observe the complete composition of firms' investment, which is the focus of this paper.

The 1998 ACES sampling frame consists of all U.S. private, nonfarm employers. $^{20}$ All companies with 500 or more employees were surveyed while smaller employers were surveyed based on a stratified random sampling such that larger firms were sampled with a higher probability. Response to the ACES is legally required so response rates are extremely high. In the end, responses were obtained from nearly 34,000 firms, with around 28,000 reporting some positive investment.

Unfortunately, aside from sales, book value of total capital assets, and invest-

\footnotetext{
${ }^{18}$ For more details regarding the 1998 Annual Capital Expenditures Survey, including the published aggregate data and the actual survey questionaires, see Census Bureau [2000].

${ }^{19}$ The ACES is the primary source of data used by the BEA to construct estimates of aggregate investment for non-manufacturing industries. As described below, the 1998 ACES collected data on investment by detailed asset type; this information is now being used by the BEA in constructing its Capital Flows Tables and its Fixed Reproducible Tangible Wealth estimates, but only in a very limited way. See Becker, Haltiwanger, Jarmin, Klimek, and Wilson [2004] for more on this issue.

${ }^{20}$ In addition, a sample of companies with zero employees were sent an abbreviated questionaire which did not request the disaggregate investment detail.
} 
ment, the ACES does not collect information on other key variables needed for productivity analysis. Most importantly, ACES does not record employment levels. To obtain data on these other variables, I match the ACES data to the Compustat research file. ${ }^{21}$ The drawback of this merger is that Compustat only covers publicly-traded companies, which are a small subset of the firms in ACES (as in the overall economy), albeit a subset of very large firms that account for a large share of U.S. economic activity. ${ }^{22}$ Matching ACES to Compustat in 1998 yields a sample of roughly 3,000 firms (though about half of these firms had missing values for at least one of the variables needed for the productivity regressions below). An advantage of merging with Compustat, though, in addition to its provision of key productivity-related variables, is that it provides an annual time-series of data. The majority of firms in the 1998 matched sample were also present in Compustat in 1999-2001, allowing us to observe the relationship between investment composition and productivity in future years as well as the current year. Most of the matching firms are also included in Compustat in 1995-1997, which allows us to test for reverse causality to some extent.

\subsection{Investment Patterns and Summary Statistics}

Before getting into the analysis of the relationship between the composition of capital (across types) and productivity residuals, it is useful to consider the relevant patterns that have been found regarding disaggregate investment behavior at the micro-level as well as the basic characteristics of our sample. Wilson [2004] uses the full 1998 ACES sample, with around 28,000 firms, to establish a number of interesting stylized facts about firms' investment behavior in terms of heterogeneous capital. Two of those findings are of particular relevance here.

First, he finds that investment (at least reported investment) tends to be con-

\footnotetext{
${ }^{21}$ A bridge file linking Compustat's unique firm identifier, CUSIP, with the unique firm identifier in the ACES was generously provided (and constructed) by Ron Jarmin and Kristen McCue of the Center for Economic Studies, U.S. Census Bureau.

${ }^{22}$ Another, more minor, drawback of the Compustat data in this context is that Compustat data on sales, labor, capital book value, and materials costs are global, while the investment data in ACES is U.S. only. In the empirical exercises below, I assume that the domestic investment shares from ACES are a reasonable proxy for global investment shares. This should be a valid assumption given that in the ACES-Compustat merged sample, the ratio of ACES fixed assets and Compustat fixed assets is near one for most of the sample (with a median of 0.924 , a 25th percentile of 0.725 , and a 75 th percentile of 0.999$)$.
} 
centrated in a small number of capital types, though what exactly these types are varies from firm to firm. This is particularly true for structures capital: $72 \%$ of the firms that reported having some structures investment did so in only a single structure type (only $11 \%$ had investment in more than two types) ${ }^{23}$; yet no single structure type averages more than $20 \%$ of total structures for these firms. Equipment investment tends to be more diverse across types. For instance, $55 \%$ of equipment-buying firms had investment in three or more types of equipment. For both equipment and structures, investment diversity tends to increase with firm size. In particular, among firms at or above the 90th percentile of sales - a group which roughly corresponds to the Compustat sample - over $70 \%$ invested in three or more types of equipment, $25 \%$ invested in three or more types of structures. These statistics imply that for many types of capital, especially structure types, investment is a rather uncommon phenomenon. Thus, the contribution of these capital types to productivity may be exceedingly difficult to identify. For this reason, I decided to condense the 55 ACES type categories down to 20 types in order to reduce the frequency of zeros in the investment shares, and hence increase their cross-sectional variability. ${ }^{24}$ The mapping from the original 55 ACES categories to the 20 categories used in this paper is shown in Table 1.

The average number of different equipment types that these businesses bought was 4.6. Not surprisingly, the average number of structure types was much lower, at 1.7. On average, they spent $15 \%$ of their total capital expenditures on Computers, $16 \%$ on Special Industry Machinery, 11\% on Miscellaneous Equipment, and less than 10\% on each other capital type. The lowest average investment share is $1 \%$ (for Trucks). It is interesting to note that firms in the sample reported much less investment, on average, on Software and Communications Equipment, each with about $3 \%$ of total investment, than on Computers. ${ }^{25}$

\footnotetext{
${ }^{23} 39 \%$ of the firms in ACES had at least some structures investment; $78 \%$ had some equipment investment.

${ }^{24}$ In addition, as a robustness check on the main regression results reported below, I tried excluding firms which reported investment in fewer than 3 capital types (at the 20-type level). This had virtually no effect on the regression results, as this restriction excluded very few firms from our sample.

${ }^{25}$ This contrasts with National Income and Product Accounts (NIPA) data which shows Software investment in 1998 was actually slightly greater than Computer investment. The difference likely comes from how ACES and NIPA treat expensed software. In the ACES, firms are instructed to report investment in software "only if capitalized as part of a tangible asset" and to exclude it "if the purchase is considered intangible (e.g., licensing agreement) or if expensed such as office supplies." The NIPAs, on the other hand, classify all software expenditures as investment regardless of whether
} 
The second finding from Wilson [2004] of particular relevance here is that capital goods vary greatly in terms of how widely used they are among industries. Of the 55 capital types shown in Table 1, Computers are the most widely used, followed by Software. ${ }^{26}$ For instance, using the sample weights in the ACES to get an appropriate economy-wide estimate, the top four Computer-investing industries accounted for only $24 \%$ of all Computer investment in 1998. For Software, this "top-4 industry concentration ratio" was just $26 \% .{ }^{27}$ This seems to confirm the common perception of these capital types as "general purpose technologies." Other widely purchased capital goods were "Other Office Equipment" and "Manufacturing, Processing, and Assembly Plants." Conversely, many other capital goods, especially structure types, are extremely concentrated in just a few industries (with top-4 industry concentration ratios above $90 \%)$.

These findings affect the interpretation of the coefficients on the type-specific investment shares in our regressions. The regressions contain 3-digit SIC industry dummies, but if a capital good tends to be highly concentrated, what we may be identifying with its share coefficient is actually an industry effect below the 3-digit level. In the description below of the regression results, the focus is generally on the "general purpose" capital goods such as Computers, Software, Instruments, Fabricated Metal Products, etc.. Other asset categories, particularly structures, are predominately industry-specific asset types. Their inclusion in these regressions serves more to control for industry effects not accounted for by the 3-digit SIC industry dummies.

Now, let us turn briefly to the basic characteristics of our regression sample. Table 2 provides summary statistics for the main variables used in the analysis below. One can see here that the firms in this sample are indeed quite large. Sales among these firms averaged roughly $\$ 2.3$ billion in 1998 and they employed an average of 12,447 workers. These firms collectively accounted about $28 \%$ of gross output and $19 \%$

the firm accounts for the expenditures as capital or intermediate expenses. Note that software that is bundled with, or embedded in, hardware is not counted as software investment in either ACES or NIPAs. The 2003 ACES, which like the 1998 survey will request investment by detailed asset type, will also include a supplemental survey requesting the amounts expensed on Computers, Communications Equipment, Software, and Instruments.

${ }^{26}$ Throughout the paper, capital type names are capitalized to indicate that they refer to specific categories of capital listed in Table 1.

${ }^{27}$ Somewhat surprisingly, Communications Equipment turned out to be rather concentrated, with an industry concentration ratio of $87 \%$. 
of employment in the U.S. private nonfarm economy. ${ }^{28}$

It is also worth noting the raw correlations between sales and each of the variables in our regressions. These are shown in the last column of Table 2. Interestingly, Computers have virtually no correlation with sales and Software is actually negatively correlated with sales, even though, as shown below, these capital types are positively associated with sales in a multivariate production function regression analysis.

\section{Results of cross-sectional regressions}

\subsection{Production Function Regressions}

Tables 3-5 present the main results of the cross-sectional regressions (described above in Section 3. Table 3 presents the estimates of the parameters in equation 3 . In parentheses, robust (Huber-White) standard errors are shown. The first column of results pertains to a regression containing only 1998 variables. Results in the second column are from a regression where all variables are 1999 values, except the investment shares (which are only available in 1998). The third and fourth columns refer to regressions for 2000 and 2001, respectively. The dependent variable is log gross output (sales); the independent variables are log labor (number of employees), log capital stock (deflated book value), all investment shares except one (Special Industry Machinery) ${ }^{29}$, and dummy variables controlling for 3-digit industry, state of the firm's headquarters, the employment size class of the firm, and whether the firm engaged in an investment spike in 1998. The coefficients on the industry and state dummies are not disclosed in order to avoid confidentiality concerns.

\footnotetext{
${ }^{28}$ The sales figures here are based on the Compustat Net Sales variable (\#A12). Total sales for the sample was $\$ 3.871$ trillion and total employment was 20.588 million. According to the BEA's gross output by industry data, private nonfarm gross output in 1998 was $\$ 13.961$ trillion. Total private nonfarm employment in 1998 was 106.021 million (from BLS Earnings and Employment).

${ }^{29}$ One investment share must be omitted to avoid linear dependence of the investment shares. This is consistent with the model in Section 3 , as there we defined $\theta_{p}$ relative to some numeraire type, $\theta_{0}$. Special Industry Machinery was chosen as the omitted category based on the a priori expectation that it has a lower marginal product than most other capital goods. Though the level of the coefficient on each investment share depends on the choice of omitted category, this choice does not affect the coefficient relative to other types' coefficients. Moreover, for consistency, below when I compare the estimated coefficients to user cost measures from the BLS, the BLS measures are also expressed relative to Special Industry Machinery.
} 
We include the investment spike dummy because firms with an investment spike may incur high adjustment costs in 1998 and subsequent years which will be reflected in lower output and productivity than they otherwise would obtain. Conversely, the spike may reflect the firm's response to a positive productivity shock (similar to how investment is argued to reflect unobserved productivity shocks in Olley and Pakes [1996]). Either way, it should be included in our regressions since investment spikes may consist disproportionately of certain capital goods, thus excluding the spike variable could bias the coefficients on the investment shares of those capital goods.

The results show that Computers, Communications Equipment, Software, and Offices are statistically significantly associated, above the $99 \%$ level, with higher multifactor productivity (i.e., output controlling for capital and labor) for all four years in our sample, 1998-2001. The computer coefficient is generally around 0.5, suggesting that an increase in the computer investment share by 10 percentage points (relative to the omitted capital type) would be expected to be associated with $5 \%$ higher multi-factor productivity (since we're controlling for capital and labor). The computer-productivity link appears to be slightly higher in 1998 and 1999 than in 2000 and 2001 (though the differences are not statistically significant). Software and Communications Equipment have even larger effects. Software's coefficient is 0.81 is 1998, 0.79 in 1999 and declines thereafter to 0.62-0.67 in 2000 and 2001. Communications Equipment's coefficient is essentially flat over these four years, ranging from 0.70-0.74. A closer look at how these coefficients vary over time is presented in Section 6 .

The investment share for Offices has a coefficient that hovers near 0.60. It seems unlikely that this positive association between Office Building investment and productivity represents a causal impact of such investment on productivity. Rather, it is more likely that Office investment is proxying for unobserved intangible factors, such as organizational capital (e.g., human resource management programs, advanced management systems, brand development/marketing, and development of distribution channels). In Section 6 below, I provide evidence that this is indeed the case: including a proxy for organization capital in the above regression leaves the coefficient on Offices economically and statistically insignificant, while the coefficients on Computers, Communications Equipment, and Software remain positive and significant (though reduced, possibly due to a measurement-error-induced bias discussed in that section).

There are a few other notable results in Table 3. I estimate the elasticity of output with respect to labor to be $.49-.53$ and the elasticity of output with respect to 
capital to be .41-.44. These estimates are reasonable, though the estimates of labor's elasticity are somewhat below that implied by factor shares while capital's elasticity estimates are somewhat above. The coefficient on the spike variable is positive and significant for 1998 and 1999. Its value implies that a spike is associated with 7-8\% higher output in the current and following year. The effect becomes smaller and insignificant in subsequent years. Firm size, as proxied by employment size, has no significant relationship with productivity in these regression, all else equal (which is not surprising given that $\log (L)$ is already included in the regression).

\subsection{Labor productivity and $2 \mathrm{FP}$ regressions}

Overall, the results from the labor productivity regressions, shown in Table 4, are nearly identical to those from the production function regressions discussed above. As in the production function regressions, Computers, Communications Equipment, and Software are statistically significantly associated, usually at the $99 \%$ level, with higher productivity for all four years in our sample, 1998-2001. The coefficient values and the time path of coefficients on these types is also similar to those in Table 3. Also as in the production function regressions, Offices are positively and significantly (at above the $99 \%$ level) associated with labor productivity for all four years in our sample, while Aircraft investment is negative and significant in 2000 and General Purpose Machinery is positive and significant in 2001.

The coefficient on the capital-labor ratio implies an elasticity of output with respect to capital of .40 to .45 , which is reasonable though perhaps slightly higher than expectations. The spike variable is found to have the same effect in the labor productivity regression as in the production function regression: a spike is associated with $7-8 \%$ higher labor productivity in the current and following year, with the coefficient becoming smaller and insignificant in subsequent years.

As discussed in Section 3, one can also estimate the set of parameters $\left\{\theta_{p}\right\}$ using a multi-factor productivity specification. When we use $2 \mathrm{FP}$ as the dependent variable and regress it on the investment shares, the precision of the estimates of the investment share coefficients is reduced (relative to the production function or labor productivity specifications). This is likely because the measure of $2 \mathrm{FP}$, which relies on observed factor shares, contains a good deal of noise - stemming mostly from the fact that labor expenses had to be imputed for the majority of firms due to frequent nonreporting of labor expenses in Compustat. Nonetheless, the results with $2 \mathrm{FP}$ as 
the dependent variable are broadly consistent with those from the production function or labor productivity regressions.

The results of the $2 \mathrm{FP}$ regressions are shown in Table 5. Again, evidence is found of a positive and significant relationship between investment and multi-factor productivity for Computers, Communications Equipment, Software, and Offices. These relationships are found in all four years, with the exception of Communications Equipment in 1998 and Computers in 2001 (in both cases, the estimated coefficient has a p-value just over 10\%).

\subsection{Interpretation of Results}

In section 3 , I showed that the coefficient on a particular investment share represents $\alpha \theta_{p}=\alpha\left[\left(F_{p} / F_{0}\right)-1\right]\left(\delta / \delta_{p}\right)$, i.e., the (ex-post) marginal product of the capital type (relative to the omitted type), adjusted for its relative depreciation rate, times the elasticity of capital in the production function. Under the Neoclassical assumption that firms equilibrate marginal products to factor prices, this coefficient should thus equal $\alpha\left[\left(c_{p} / c_{0}\right)-1\right]\left(\delta / \delta_{p}\right)$, where $\alpha$ is the elasticity of capital; $c_{p}$ and $c_{0}$ are the user costs for type- $p$ and type- 0 capital, respectively; and $\delta$ and $\delta_{p}$ are the depreciation rates for total capital and type- $p$ capital, respectively. The U.S. Bureau of Labor Statistics (BLS) provides estimates of depreciation rates, as well as estimates of user costs, at a detailed capital type level (which has a many-to-one mapping to our 20-type level). The data are widely used by researchers and other government agencies in the construction of capital stock data. Using our estimate of $\alpha$, along with the BLS measures of $\delta$ and $\delta_{p}$, one can thus back out the implied ratio of marginal products between capital type $p$ and the numeraire capital type. Further, taking the BLS estimate of the user cost of the numeraire type - in our case, Special Industry Machinery - as approximately equal to the marginal product of this capital type, one can back out the marginal product (per dollar of capital) for every capital type.

Using the coefficient estimates from the baseline regression results for 1998, the implied marginal products by type of capital are shown in Table 6 and Figure 2 . Column (1) of Table 6 shows the implied marginal products based on the production function regression results shown in column (1) of Table 3. Columns (2) and (3) show implied marginal products based on the labor productivity and 2FP regressions, respectively. The fourth column provides the user cost estimates for 1998 provided by 
the BLS. ${ }^{30}$ The asterisks next to each implied marginal product indicate the degree to which it is statistically significantly different from the BLS estimated user cost. The confidence intervals here assume that everything in the expression $\alpha\left[\left(c_{p} / c_{0}\right)-1\right]\left(\delta / \delta_{p}\right)$ is known with certainty except the variable of interest, $c_{p}$.

For most capital types, the implied marginal product is strikingly similar to the BLS user cost. This is especially true if one uses the production function or labor productivity estimates. For instance, for Miscellaneous Equipment, Metalworking Machinery, Instruments, General Purpose Machinery, Fabricated Metal Products, Other Structures, and Aircraft, the difference between the implied marginal product (from the production function estimation) and BLS user cost is within just three percentage points. For a several capital types, however, the implied marginal product is found to be significantly (statistically and economically) higher than the BLS estimate of the user cost. In particular, using the production function estimates, Computers are found to have had an ex-post marginal product of $66 \%$ in 1998, compared to the BLS's estimated user cost of $43 \%$. Communications Equipment had an estimated marginal product of $33 \%$, compared to a $16 \%$ estimated user cost. Software had an estimated marginal product more than the BLS's user cost, $119 \%$ vs. $48 \%$. This says that one must pay $\$ 1.19$ in order to rent $\$ 1$ worth of software for a year. One must pay more than $\$ 1$ because its value depreciates so quickly that in order to get an entire year's worth of service flow from software (at a constant quality), one must pay more than $\$ 1$ in rent. To put it differently, to provide oneself with $\$ 1$ worth of service flow for a year, one would need to buy $\$ 1$ worth of software more than once during the year.

The estimated marginal products for Commercial Buildings, Industrial Buildings, Offices, Utility Structures, and Other Structures are also statistically significantly higher than their BLS user costs. However, this result should be viewed with caution. First, though statistically significant, the differences for these types are rather minor (ranging from 4-8 percentage points). Second, as noted earlier, structures capital tends to be infrequent and heavily concentrated among industries. Therefore, the estimated coefficients on their investment shares may, to some extent, reflect industry effects not picked up by the 3-digit industry dummies included in the regressions.

As mentioned in Section 3, there are a number of possible reasons why the estimated ex-post marginal product for a capital good could be different than its user cost

\footnotetext{
${ }^{30}$ The BLS actually estimates user costs (rental prices) by asset type and industry. To arrive at a single user cost estimate for each asset type, I simply average across all industries.
} 
(assuming the user cost is not mismeasured). First, there could be adjustment costs, including learning costs, that disproportionately affect particular capital goods. Second, certain capital goods may be associated with unobserved organizational co-investments. For example, a number of authors have argued that organization co-investments, such as human resource management (HRM) programs, training programs, quality control systems, etc., contribute to productivity and are facilitated by ICT capital. ${ }^{31}$ Third, due to uncertainty regarding the rate of return on capital investments, there could be systematic expectational errors by firms that may be more severe for certain capital goods. For instance, it is often posited that firms systematically overinvested in Communications Equipment in the late 1990s. Interestingly, though, I find that in fact the marginal product on Communications Equipment during this period was actually above its user cost.

\subsection{Robustness Checks}

In the regression specifications thus far, intermediate inputs (materials, $M$ ) were not included in the gross output production function as we maintained that value added and materials are weakly separable. I now relax that assumption as a robustness check. Assuming that gross output is a Cobb-Douglas function of $K, L$, and $M$, one can derive two additional specifications. The first specification is identical to the production function specification above (equation (3)) except that it includes log materials as an additional regressor. The point estimates and significance of the investment share coefficient are not qualitatively affected by this change (and therefore are not shown).

As another robustness check related to materials, I estimate the $2 \mathrm{FP}$ specification using double-deflated value added instead of gross output in the construction of 2FP. The drawbacks of this approach are (1) that we lack separate deflators for gross output and materials to use in the double deflation, and (2) the double-deflated value added measure may be biased under imperfect competition (Basu \& Fernald [1996]). Using this alternative measure of $2 \mathrm{FP}$ yields similar results to those obtained using the gross output version of $2 \mathrm{FP}$, though the estimates are somewhat less precise.

Another alternative way to measure $2 \mathrm{FP}$ in this paper is to use the reported sales data collected in ACES rather than the sales data collected in Compustat. Obvi-

\footnotetext{
${ }^{31}$ See, e.g., Bartel, Ichniowski, and Shaw [2004a]; Black and Lynch [2001]; Bresnahan, Brynjolfsson, and Hitt [2001].
} 
ously, since the ACES data cover only 1998, we can only construct this ACES version of $2 \mathrm{FP}$ (gross output) for 1998. If we use the ACES version of $2 \mathrm{FP}$ in our 1998 regression (full specification), again Computers are found to have a positive and highly significant (above $99 \%$ level) relationship with $2 \mathrm{FP}$. This regression also yields positive and significant coefficients on Communication Equipment and Cars \& Light Trucks.

In sum, our various alternative regressions are virtually unanimous in finding a positive and statistically significant relationship between Computer's share of investment and productivity. This is true for productivity in the current year and at least the subsequent three years, though the effect appears to be strongest for productivity one year out. Communications Equipment and Software are also found to have a significant positive relationship with productivity in the majority of our regressions. Other capital types are occasionally found to be significantly related to productivity, but for none, except Office Buildings, is the relationship particularly robust. As mentioned earlier, since investment in structures is heavily determined by industry, the association between structures types, such as Office Buildings, and productivity may be reflecting industry effects not fully captured by the 3-digit industry dummies.

\subsection{Manufacturing vs. Nonmanufacturing}

It is conceivable that certain capital goods would have different ex-post rates of return in manufacturing than in nonmanufacturing. Since the same capital good may be used for different purposes in manufacturing than it would in nonmanufacturing, there could be differences between the two sectors in the degree of adjustment costs, the organizational co-investments, and errors in expectations as to the return from investment in the capital good. Therefore, an interesting extension of the regressions discussed above is to allow the coefficients to vary between manufacturing and nonmanufacturing. To implement this extension, I create a manufacturing dummy variable and then include interactions between it and each of the regressors in the baseline production function regression above (Table 3). The results are shown in Table 7. Columns (1), (3), (5), and (7) show the estimated coefficients (and standard errors) on the non-interacted terms, while Columns (2), (4), (6), and (8) shows the estimated coefficients on the manufacturing interactions.

As for the overall sample, Computers, Communications Equipment, Software, and Office Buildings are found to be positively and significantly related to productivity in the non-manufacturing sector in 1998 (at the 10\% level or better). Office Equip- 
ment also has a positive and significant coefficient in 1998, while Fabricated Metal Products has a negative and significant coefficient. In 1999, only Computer, Communications Equipment, and Software are statistically significant for non-manufacturing. In 2000 and 2001, only Communications Equipment is positive and significant (though a number of types are negatively significant).

As for the manufacturing interactions, I find that Commercial Buildings, Electrical Equipment, Fabricated Metal Products, and Instruments each have significantly higher coefficients in the manufacturing sector than in non-manufacturing in 1998. Office Equipment, on the other hand, has a significantly lower coefficient. For 1999-2001, Instruments and Offices have significantly higher coefficients in manufacturing; moreover, the net effect in manufacturing for these two types also is positive and significant for these years. Commercial Buildings and Electrical Equipment also have significantly higher coefficients in 2000 and 2001.

The higher return on Instruments in manufacturing may be because the kinds of instruments used in manufacturing are actually different than those used in nonmanufacturing (e.g., scientific/measuring instruments instead of medical instruments) - perhaps the kinds used in manufacturing tend to have higher returns. The higher estimated coefficient for Commercial Buildings may be due to the fact that these are categories of structures not typically associated with manufacturing. A high investment share in one of them by a manufacturing firm may reflect that the firm is highly diversified. Therefore, the higher returns to these structures in manufacturing may reflect that diversified firms have higher productivity than non-diversified firms, whereas in nonmanufacturing, ownership of these structures does not indicate an advantage in industrial diversity/scope.

\section{Causality}

As mentioned in Section 3, a common concern in production function estimation is simultaneity bias, which could arise if there is an unobserved productivity component that simultaneously affects the input decisions and the output realization. This is of particular concern in cross-sectional regressions since one cannot difference-out even non-time-varying unobserved productivity components. In this section, I present the results of a number of different approaches to alleviating this potential bias and/or to assessing the extent of the problem. 


\subsection{Analyzing how estimates vary over time}

In addition to the regressions for 1998-2001, one can also estimate regressions for years prior to the investment composition decision. For any particular capital type, the precision of our estimator is not sufficient to statistically reject that the time path is flat. Nonetheless, visually inspecting these time paths is suggestive of the direction of causality. Therefore, I estimate the cross-sectional production function regressions discussed above for 1995-1997, in addition to the 1998-2001 regressions and plot the estimated coefficients for the capital goods found to be significantly associated with productivity in the production function regressions above (Table 3): Computers, Communications Equipment, Software, and Offices. The result is shown in Figure 1. The estimated coefficients for Communications Equipment are clearly higher in and after 1998 than before 1998, suggesting that the predominant direction of causality is from the investment decision to productivity. The opposite is true for Offices, suggesting productivity, or slow-moving firm effects like organizational capital that are correlated with productivity, causes investment in Office Buildings (e.g., for expansion purposes). For Software and Computers, the estimates prior to 1998 are not much different from their values after 1998. This suggests that either investment shares for these capital goods are highly autocorrelated, there are important unobserved firm fixed effects (correlated with these capital types), or both. Below, I attempt to estimate firm "fixed" effects separately for the pre-1998 and post-1998 periods and evaluate whether their correlation with the investment shares is stronger in one period than the other.

First, though, it is worthwhile to take a moment to consider the time path of the coefficients in Figure 1 from 1998 onward. These paths may reflect the adjustment processes involved with the different capital types (though they may also reflect changes in organizational co-investments). The coefficient on Communications Equipment stays around 0.70-0.74 for all four years. This may indicate that the investment immediately raises productivity and then, due to continued learning or adjustment, it continues to benefit productivity for a number of years. The coefficients on Computers and Software, on the other hand, drop considerably (though not statistically significantly) after 1999, suggesting that software may require less of an adjustment process. 


\section{2 "Fixed" Effects Before and After the Investment Decision}

The results above indicate that unobserved firm fixed effects may be an important omitted variable in our regressions. Unfortunately, it is impossible to fully account for the potential effect of firm fixed effects with cross-sectional data. I do, however, have panel data for all of the variables in the model except the investment shares. Hence, it is possible to estimate firm fixed effects using the Compustat data, though obviously these fixed effects will not be orthogonal to capital mix.

These fixed effects should contain useful information. Consider estimating cross-sectional regressions of the form in equation (3) but without the investment shares. One can estimate such a cross-sectional regression separately for a number of years. The estimated residuals can be averaged over those years to obtain an estimate of the firm "fixed" effect for that period. "Fixed" is in quotations here as these effects are not, strictly speaking, fixed. Rather, they are persistent - changing period-to-period instead of year-to-year. The averaging has the advantage of removing some of the year-to-year noise in the data. The fixed effects, then, should capture slow-moving (persistent) and/or permanent firm factors that affect productivity (as measured). These factors include unobserved labor quality, workplace practices (e.g., HRM practices), co-investments, and other so-called "intangible capital." Lev and Radhakrishnan [2003], in fact, measure intangible capital in exactly this way, as the fixed effect from a production function estimation using Compustat data. Thus, an interesting question is whether these fixed effects are related to the capital mix and how. Furthermore, does capital mix have a greater relationship with the post-1998 fixed effect than it does with the pre-1998 effect, suggesting a causal link from capital mix to productivity? Finally, does capital mix affect the difference between the post-1998 and pre-1998 effects, suggesting a link from capital mix to productivity growth?

To answer these questions, first I estimate two sets of fixed effects, one for a period just before the 1998 observed investment mix decisions are made, 1995-97, and one for a period just after, 1999-2001. To estimate a period's fixed effect, I obtain the residuals, for each year, from the cross-sectional production function regression described above (equation 3), and then average the residuals, within firm, across the years of the period. I then regress each of these period's fixed effects on the 1998 investment shares. ${ }^{32}$ If the permanent factors in intangible capital affect firms' cap-

\footnotetext{
${ }^{32}$ Black and Lynch [2001] follow a similar approach in evaluating the impact of workplace practices on productivity, given a single year's data on workplace practices: First, they estimate a standard
} 
ital mix decisions, then we should find statistically significant nonzero coefficients on investment shares in both of these two regressions. This finding would suggest that permanent factors have an effect on capital mix, though this does not preclude the possibility that capital mix has a causal effect on productivity as well. On the other hand, if we find that the investment shares are significantly larger in the latter period's regression, then it must be the case that the capital mix does indeed have a causal effect on productivity.

The results of these regressions are shown in Table 8. The first column of coefficient estimates are from a regression of the pre-1998 (1995-1997) fixed effect on each of the investment shares. As in the earlier regressions, Special Industry Machinery is the omitted category. A number of capital types have a statistically significant relationship with the pre-1998 fixed effect.

The fact that investment in 1998 in these types of capital are significantly related to productivity fixed effects in the pre-1998 period suggests that intangible/organizational capital (i.e., the slow-moving and permanent productivity factors, including human capital, captured by the fixed effects) does affect the investment composition decision. Not surprisingly, firms with high levels of organizational capital tend to subsequently invest in Computers, Software, Communications Equipment, and Offices - capital typically associated with innovative workplace practices, high labor quality, etc.. Such firms also appear to invest relatively more in General Purpose Machinery and Industrial Buildings.

The second column of estimates in Table 8 shows the results from regressing the post-1998 (1999-2001) fixed effect on the investment shares. In general, the same capital types that were found to be associated with pre-1998 average productivity are found to be associated (in the same direction) with post-1998 average productivity, and there is little difference in the coefficient estimates before and after 1998. This suggests that there is an important permanent component in these fixed effects that is related to capital mix. However, it is worth noting that while the differences are not

production function using establishment-level panel data and using the within or GMM estimator to account for the transmitted unobserved productivity component $\left(\omega_{i t}\right.$ in our model). They then average the residuals over the period 1987-93 to obtain establishment fixed effects. Lastly, they regress these fixed effects on firm-level measures of workplace practices (including human capital investments and computer usage) from a 1994 survey. My approach is an extension of this technique in that I perform the analysis for both a pre-survey period and a post-survey period in order to identify the direction of causality between the survey variables and productivity. 
statistically significant, the coefficients rise after 1998 for Computers, Communications Equipment, and Software while the coefficient on Offices falls substantially, which is at least consistent with the former three types having some causal impact and Office investment being caused in part by productivity and productivity-enhancing unobserved factors like organizational capital.

Another interesting question is whether capital mix has an effect on productivity growth? To answer this question, I regress the difference between the post-1998 effect and the pre-1998 fixed effects on the investment shares. This difference represents the (percentage) change in productivity between the pre-1998 period and the post-1998 period. The estimated coefficients on the investment shares are shown in the last column of Table 8 .

I find that investment in Communications Equipment and Fabricated Metal Products is positively and significantly related to the growth in productivity between the two periods, while Offices and Aircraft are negatively related to productivity growth. This OLS regression of the difference in fixed effects on investment shares cannot control for the possibility of reverse causality. For instance, it is possible that there was some omitted dynamic factor that affected productivity growth between the pre-1998 and post-1998 periods and simultaneously affected the capital mix (e.g., a new CEO hired in 1998). Nonetheless, it seems likely that most of the association between capital mix and productivity growth is causal.

\subsection{Proxying for Unobserved Productivity Shocks}

Given the above evidence that the baseline results may be affected by unobserved productivity components that are known ("transmitted") to the firm ex-ante, in this subsection I discuss three techniques that attempt to directly control for the unobserved component in the regression.

\subsubsection{Olley-Pakes Approach}

One technique to address simultaneity bias is that proposed by Olley and Pakes [1996]. They demonstrate that under certain conditions, the unobserved productivity shock, $\omega_{i t}$, may be proxied by a function of current investment, capital stock, and age (and their cross-terms). That is, $\omega_{i t}=g\left(I_{i t}, k_{i t}, a g e_{i t}\right)$. They suggest using a kernel estimator or a 3rd-order polynomial to approximate $g()$. 
Thus, as a robustness check on our results, I include a third-order polynomial of $I, k$, and age (including cross-terms) in addition to the other regressors. I find that this addition has virtually no effect on the results, though the output elasticities with respect to labor and capital do move slightly closer to their factor shares. ${ }^{33}$

\subsubsection{Future MFP as a proxy for unobserved productivity}

In a similar spirit, another possible method for accounting for the unobserved, transmitted productivity component is to include a measure of future productivity in the contemporaneous regression. If productivity shocks, $\omega_{i t}$, are serially correlated, future productivity may serve as an indicator of current productivity. In addition, future productivity may reflect the fixed productivity component, $f_{i}$, as well, so that future productivity may be an indicator of the entire transmitted productivity component, $\omega_{i t}+f_{i}$. The drawback of this approach is that if future productivity is caused, in part, by the current capital mix, then including future productivity will introduce multicollinearity and thereby reduce the precision of the estimators of $\left\{\theta_{p}\right\}$. As a robustness check on the baseline results, though, this drawback becomes an advantage as it reduces the likelihood of falsely obtaining statistically significant estimates of $\left\{\theta_{p}\right\}$.

To implement this approach, I include $2 f p_{t+1}$ as an additional regressor in the regressions for $t=1998-2000$. The estimated coefficients on the investment shares are not materially affected. ${ }^{34}$ As expected given the likelihood of introducing multicollinearity, the standard errors on these coefficients are increased somewhat, but nevertheless, Computers, Communications Equipment, Software, and Offices remain positively and significantly associated with current productivity, with little change in the value of their coefficients. An exception is that Software is no longer significant in the 1998 regression, though it remains significant at the $99 \%$ level is the 1999 and 2000 regressions. The only other notable change is that General Purpose Machinery now becomes significant (positive) in the 1999 regression (at the $99 \%$ level) and the 2000 regression (at the $90 \%$ level). It is also interesting to note that the coefficients on capital and labor move much closer to their average factor shares, as was also the case in the results from the Olley-Pakes approach.

\footnotetext{
${ }^{33}$ These results are considered a robustness check rather than as part of the baseline results since other studies have shown that the Olley-Pakes conditions may frequently be violated in practice. See, e.g., [37]. The results of these regressions are available from the author upon request.

${ }^{34}$ The results for these regressions are available from the author upon request.
} 


\subsubsection{Proxying for Organizational Capital}

Lev and Radhakrishnan [2003], among others, have argued that firm-level organizational capital can be proxied by a firm's selling, general, and administrative (SGA) expenses, which include spending on employee training, marketing, distribution, IT expenses (non-capitalized), etc.. The fixed productivity effect as well as the transmitted productivity shock are both likely to be strongly correlated with organizational capital, and hence SGA. Therefore, including (log) SGA as an additional regressor in our main production function regression serves to partially control for the unobserved productivity components.

Table 9 shows the results of this regression for each year 1998-2001. Focusing first on the 1998 regression, notice that the coefficients on the investment shares for several capital types are reduced considerably compared with the analogous coefficients from Table 3. Most importantly, the previous association between Office Building investment and the productivity residual is eliminated (its coefficient estimate drops from 0.57 , significant at the $1 \%$ level, to 0.09 , which is insignificant at all standard levels). Thus, it appears that this previous association for Office Building was spurious and driven by the fact that Office Building investment is highly correlated with organizational capital which likely has a positive effect on total-factor productivity. Interestingly, the coefficient on Office Equipment, another category one would expect to be highly correlated with organizational capital, also declines considerably, from 0.30 to -0.06 (though the estimator's precision is not sufficient to say the difference is statistically significant).

Note also that the coefficients in 1998 for Computers, Communications Equipment, and Software are reduced, though they remain statistically significant and positive. Using the same approach as before to back out the implied marginal products, these coefficient imply marginal products of $0.33,0.28$, and 0.57 for Computer, Communications Equipment, and Software, respectively. ${ }^{35}$ These estimates compare to the previous estimates (from Table 6) of 0.66, 0.33, and 1.19 and to the BLS rental price estimates of $0.43,0.16$, and 0.48 . The decline in the implied marginal product due to the inclusion of SGA is especially large for Computers and Software. Part of the decline is likely due to the fact that a large share of true computer and software investment is expensed by companies rather than reported as capital expenditure and

\footnotetext{
${ }^{35}$ The implied marginal products for the other capital types are essentially unchanged from Table 6 except that for Offices, which goes from 0.20 to 0.15 .
} 
therefore show up in selling, general, and administrative expenses. Thus, the inclusion of SGA may be misattributing some of the productivity contribution of computers and software to organizational capital, i.e., causing a downward bias in the estimator on Computer and Software investment shares. This is likely to be especially problematic for Software (see footnote 26). This is the reason that I do not start off including SGA in the regressions discussed in Section 5.

Looking at the results for 1999-2001, there are several interesting findings. First, the coefficients on Computers and Software drop noticeably in 1999 and become essentially zero in 2000 and 2001. This suggests that these capital goods have an immediate impact on productivity but, consistent with their rapid depreciation rates, their impact is quite short-lived. It also suggests that their high and significant coefficients for years after 1998 found earlier (Table 3) was due to their unobserved correlation with organization capital (though, again, the coefficients on these types is likely biased downward due to the expensing issue mentioned above). Consistent with the regressions of pre-1998 and post-1998 fixed effects on investment shares (Table 8), Communication Equipment is found to have a strong and long-lasting positive effect on TFP. Finally, it interesting to note that Trucks are found to have a large and statistically significantly positive coefficient for 1999-2001. The heavy use of Trucks by a firm likely signals that the firm handles it own distribution rather than outsourcing to the transportation and warehousing services industry, the spending on which would be included in SGA expenses. Thus, the positive coefficient on Trucks here may indicate that firms handling their own distribution have an efficiency edge over those that outsource such services to other companies.

\section{Complementarities and Substitutabilities}

\subsection{Among Capital Types}

The results presented thus far establish that the standard measure of capital stock used in micro-level production functions does not adequately account for capital mix. But these results do not shed light on the fundamental question of whether it is possible at all to express capital as a single aggregate. That is, are capital goods perfectly substitutable? To answer this question, one must test whether certain "bundles" i.e., pairs, triples, quadruples, etc., of different types of capital have an impact on 
productivity above and beyond the individual effects that each type of capital have on productivity. In the standard Neoclassical production model, the cross-partial derivative for any pair of capital goods is equal to zero: $F_{p j}=0$ for $p \neq j$. This restriction can be straightforwardly tested with the ACES data.

Starting with the production function regressions discussed above (results for which are shown in Table 3), I add interactions of investment shares between every possible pair (dyad) of capital types in our data. With 20 types, this amounts to 190 interactions. ${ }^{36}$ [Results are now shown for space considerations. Contact author for actual estimates.] I find a number of significant interactions, which implies that returns (and marginal products) for particular capital goods are affected by the presence of other complimentary or substitutable capital goods. ${ }^{37}$ This result is a rejection of the perfect substitutability assumption necessary for the existence of a single capital aggregate (in a world with embodied technological change). ${ }^{38}$

It is worth highlighting a few of the most notable complementarities and sub-

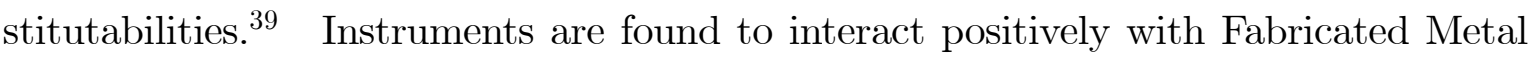

${ }^{36}$ The number of dyads in a 20 -member set is $(20 \times 19) / 2=190$. In general, the number of $n$-ads in a $G$-member set is $G ! /[n !(G-n) !]$. Using this formula, one can see that adding triad or higher- $n$ interactions, though they may have interesting real effects, would rapidly use up all of the degrees of freedom in our regressions.

${ }^{37}$ The p-value on an F-test of the hypothesis that all interactions are jointly equal to zero is less than 0.001 for all four yearly regressions.

${ }^{38}$ Without embodied technology, capital subaggregates need not necessarily be perfectly substitutable for the existence of a single capital aggregate, $K=g\left(K_{1}, K_{2}\right)$; the necessary condition is that the marginal rate of substitution between the subaggregate be independent of labor (Solow [19551956]). Solow commented that this condition "will not often be even approximately satisfied in the real world." With embodied technology, not only must this condition hold, but additionally the subaggregates must be perfectly substitutable (Fisher [1965]).

${ }^{39}$ The following interactions were found to be significant at the $95 \%$ level or higher (the sign and significance level of their coefficient is in parentheses):

Computers \& Fabricated Metal Products (+, 5\%), Computers \& Commercial Buildings (+, 1\%), Other Office Eqp. \& Aircraft (+, 1\%), Other Office Eqp. \& Misc. Eqp. (-, 5\%), Other Office Eqp. \& Other Structures (-, 1\%), Communications Eqp. \& Industrial Buildings (-, 1\%), Software \& Aircraft (-, 1\%), Software \& Other Transportation Eqp. (+, 5\%), Fabricated Metal Products \& Other Transportation Eqp. (-, 1\%), Fabricated Metal Products \& Instruments (+, 1\%), Fabricated Metal Products \& Commercial Buildings (-, 1\%), Metalworking Machinery \& Autos (-, 1\%), Metalworking Machinery \& Other Transportation Eqp. $(+, 1 \%)$, Autos \& Trucks (+1\%), Autos \& Elec. Eqp. (-5\%), Other Transportation Eqp. \& Instruments $(+, 5 \%)$, Other Transportation Eqp. \& Misc. Eqp. (+, $5 \%$ ), Misc. Eqp. \& Commercial Buildings (-, 5\%), Commercial Buildings \& Industrial Buildings (+, 
Products and Other Transportation Equipment, and negatively with Electrical Equipment. Computers interact positively with Commercial Buildings and negatively with Special Industry Machinery. Communications Equipment interact negatively with Industrial Buildings. Software interacts positively with Other (non-autos, non-aircraft) Transportation Equipment but negatively with Aircraft.

In general, the findings appear to yield a very interesting set of patterns:

(1) "high-tech" capital tends to be complementary with "low-tech" capital,

(2) "high-tech" capital tends to be substitutable with other "high-tech" capital, and

(3) "low-tech" capital tends to be substitutable with other "low-tech" capital.

These patterns are broadly the case if one groups Computers, Communications Equipment, Software, Instruments, Electrical Equipment, Metalworking Machinery ${ }^{40}$, Autos, Aerospace, and Special Industry Machinery ${ }^{41}$ into "high-tech" and Other Office Equipment, Fabricated Metal Products, Heavy Duty Trucks, Other Transportation Equipment, Miscellaneous Equipment, and all types of Structures into "low-tech" (with General Purpose Machinery somewhere in between). These classifications are not arbitrary. They would be obtained, almost exactly, if one split the list of capital types on the basis of how much R\&D expenditures are applied to each capital type in the U.S. (See Wilson [2002], who compiled such a list from NSF data). The classifications would also be obtained to a large extent if one split the list according to the implied marginal products (or, for that matter, the official BLS user costs) in Table 6 (exceptions are that Aircraft would become low-tech while Miscellaneous Equipment, Office Equipment, and Office Buildings would become high-tech).

To confirm these patterns more formally, I estimate the same model but restricting the coefficients to be equal within each of the following three groups: (1) pairs of high-tech goods, (2) pairs of low-tech goods, (3) pairs with one high-tech good $5 \%$ ), Utility Structures \& Other Structures (+, 5\%), Utility Structures \& Industrial Buildings (+, $1 \%)$, Office Buildings \& Industrial Buildings (-, 5\%), Special Industry Machinery \& Office Buildings $(+, 5 \%)$.

${ }^{40}$ For a discussion of recent major innovations in Metalworking Machinery used for valve-making (e.g., Computerized Numerical Control machines), see Bartel, Ichniowski, and Shaw [2004a, 2004b].

${ }^{41}$ As the name suggests, Special Industry Machinery is a hodge-podge of heterogeneous equipment, some of which are better described as "low-tech" (e.g., circular saws) and some of which are better described as "high-tech" (e.g., Semiconductor wafer processing eqp.). Hence, this type could arguably go into either category. 
and one low-tech good (using the high-tech/low-tech classification above ${ }^{42}$ ).

The results are shown in Table 10. As expected, interactions within the hightech/high-tech group are found to be negative (substitutes) on average, while interactions between high-tech and low-tech goods are found to be positive (complements) on average. The coefficient on the high-tech/high-tech interactions is statistically significantly negative (at the 90\% level or higher) for years 1998-2000 and the coefficient on the high-tech/low-tech interactions is statistically significantly positive in all four years 1998-2001. The coefficient, though, on the low-tech/low-tech interactions, while negative, is not statistically significant in any of the years.

These findings are consistent with the basic intuition that the more similar a pair of goods are, the more substitutable they are. Presumably, high-tech capital goods are more similar to each other than to low-tech goods. On the other hand, a number of authors have argued that high-tech investments such as computers tend to be part of a system of co-investments in complementary goods, some tangible and some intangible (Brynjolfsson \& Hitt [1997, 2002]; Bresnahan, Brynjolfsson, and Hitt [2000]). In particular, one might have expected computers and software to have been found to be complementary. That they are not (though they are not found to be substitutes either) may reflect the fact that computers typically already embody a large amount of software the day they are purchased, hence firms may choose to some extent between buying additional computers with the available pre-loaded software or buying new software for their existing computers. ${ }^{43}$ These two scenarios need not be complementary. A similar argument may apply to the relationship between computers and communications equipment.

In sum, contrary to common perceptions, the data suggest that high-tech capital goods are not in fact complementary with each other, but rather they are complementary with low-tech equipment and structures.

\subsection{Between Capital Types and Labor}

In addition to the complementarities and/or substitutabilities a capital good may have with other capital goods, it may also be complementary or substitutable with labor. In

\footnotetext{
${ }^{42}$ General Purpose Machinery was assigned to the low-tech group for the regressions whose results are shown, though assigning it to high-tech yielded similar results.

${ }^{43}$ Recall that the software category in ACES, as in the NIPAs, excludes software that is embedded in hardware.
} 
fact, recently it has often been suggested in the press that one reason U.S. employment growth coming out of the 2001 recession was weak while output and labor productivity growth was strong, whereas in past recessions employment growth tended to meet or exceed output growth in recoveries, is because the economy increasingly relies on capital technologies that are to some extent substitutes with labor. ${ }^{44}$ This argument has particular potency when it comes to explaining weak demand for low-skilled workers. In this section, I evaluate whether capital types differ in terms of their elasticity of substitution with labor.

To perform this evaluation, I extend the main production function regression to include interactions between log labor $(\ell)$ and each of the investment shares. The results are shown in Table 11; the coefficients on the non-interacted variables are shown in Column 1 while those on the interactions are shown in Column 2. Several interactions are found to be statistically significant, suggesting that capital types do differ in their elasticity of substitution with labor. As Special Industry Machinery is the omitted category for this regression (both its investment share and its interaction with labor are omitted), the coefficients in Column 2 indicate the degree of substitutability (negative coefficients) or complementarity (positive coefficients) between each capital type and labor relative to Special Industry Machinery's degree of substitutability with labor. Thus, in relative terms, Software is found to be labor-saving (substitutable with labor) while General Purpose Machinery and Trucks are found to be labor-augmenting (complementary with labor).

To give a sense of how these results change if we omitted another category, I repeat this regression omitting the General-Purpose-Machinery-labor interaction instead of that of Special Industry Machinery. The results are shown in Columns 3 and 4 of Table 10. Not surprisingly given that General Purpose Machinery was found to be relatively labor-augmenting above, this change results in many more capital types being relatively labor-saving. The interactions for Computers, Other Office Equipment, Software, Metalworking Machinery, Miscellaneous Equipment, Commercial Buildings, Utility Structures, and Offices are all found to have statistically significant negative coefficients; no type has a significant positive coefficient.

Given that it is likely that aggregate investment has shifted in recent years away from traditional equipment like General Purpose Machinery and toward the relatively

\footnotetext{
${ }^{44}$ This argument requires that there is some labor market friction so that the prevailing wage is stuck above the marginal product of labor (which has fallen because of the shift in capital composition).
} 
labor-saving capital goods above, these results support the notion that part of the explanation for the so-called "jobless recovery" may be this shift toward relatively labor-saving technologies.

\section{Conclusion}

This paper has shown that, even controlling for other simultaneous physical capital investments, investment in ICT capital is positively associated with total factor productivity at the firm-level. Investment in Offices has a similar positive association, though this association, unlike that for ICT capital goods, goes away once one controls for firms' spending on selling, general, and administrative expenses, a proxy for organizational capital. Moreover, though I find evidence that slow-moving firm-specific factors - often referred to as "intangible capital" - tend to be co-investments with ICT capital, at least part of the association appears to be causal, especially for communications equipment. At the least, these results show that the common empirical practice of assuming perfect substitutability and ignoring variation in capital mix can lead to very misleading results. More importantly, though, they suggest that the aggregate trend towards more use of ICT relative to other capital by U.S. businesses will be an important driver of productivity growth going forward.

In addition, the results presented in this paper imply that the marginal products of ICT capital goods are above official estimates of their rental prices. One possible reason is that the rental price estimates, which are used in constructing the macro and industry data used in growth accounting studies, are too low for ICT capital goods. On the other hand, there may in fact be excess returns to these capital goods. Such excess returns could be due to unobserved complementary co-investments such as labor quality, adjustment costs such as learning-by-doing, or expectational errors by firms in terms of the marginal products of their capital investments.

Another important finding in this paper is evidence of complementarities and substitutabilities among different capital goods. In particular, the predominant pattern of the results suggests that goods typically classified as "high-tech" tend to be complements with "low-tech" goods and substitutes with other "high-tech" goods. This pattern is quite sensible from an economic point of view, though it contrasts with the prevailing popular view that high-tech capital goods are generally complementary to each other. The best explanation for this discrepancy is that the high-tech 
goods considered in this paper often already embed many of the characteristics that are generally associated with many of the other high-tech goods.

Finally, I find that not only does type-specific investments affect the marginal products of other capital types, but also the marginal product of labor. In particular, I find Software to be the most labor-saving capital good, while Trucks and General Purpose Machinery are the most labor-augmenting capital goods.

A number of steps were taken in this paper to evaluate the direction of causality in the capital mix-productivity relationships. However, given the purely cross-sectional nature of the disaggregate investment data from the 1998 ACES and the large number of potentially endogenous investment shares (both a blessing and a curse of this data), it is impossible to fully disentangle the effect of investment/capital mix on productivity from possible feedback in the opposite direction. Plans for some future ACES surveys call for such disaggregate investment detail to be collected again, which may allow future research to better address this issue (as well as other issues).

\section{References}

\section{References}

[1] Arellano, Manuel, and Stephen R. Bond. "Some Tests of Specification for Panel Data: Monte Carlo Evidence and Application to Employment Equations." Review of Economic Studies 58 (1991): 277-97.

[2] Audretch, David B., and Maryann P. Feldman. "R\&D Spillovers and the Geography of Innovation and Production." American Economic Review 86, no. 3 (1996): 630-640.

[3] Bartel, Ann, Casey Ichniowski, and Kathryn Shaw. "The Effects of New Information Technologies and New Work Practices on Establishment Productivity: An "Insider" Econometric Analysis." Mimeo (2004).

[4] Bartel, Ann, Casey Ichniowski, and Kathryn Shaw. "Insider Econometrics' and the Determinants of Productivity." American Economic Association 94, no. 2 (2004): 217-22. 
[5] Basu, Susanto, and John G. Fernald. "Are Apparent Productive Spillovers a Figment of Specification Error?" Journal of Monetary Economics 36 (1995): 165-88.

[6] Becker, Randy, John C. Haltiwanger, Ron S. Jarmin, Shawn Klimek, and Daniel J. Wilson. "Micro and Macro Data Integration: The Case of Capital." Conference draft for NBER/CRIW Conference in April 2004 on the Architecture of the National Accounts. http://www.nber.org/CRIW/CRIWs04/becker.pdf.

[7] Bahk, Byong-Hyong, and Michael Gort. "Decomposing Learning By Doing in New Plants." Journal of Political Economy 101, no. 4 (1993): 561-83.

[8] Berndt, Ernst R., and Catherine J. Morrison. "High-Tech Capital Formation and Economic Performance in U.S. Manufacturing Industries: An Exploratory Analysis." Journal of Econometrics 65, no. 1 (1995): 9-43.

[9] Black, Sandra E., and Lisa M. Lynch. "How to Compete: The Impact of Workplace Practices and Information Technology on Productivity." Review of Economics and Statistics 83, no. 3 (2001): 434-45.

[10] Bresnahan, Timothy, Erik Brynjolfsson, and Lorin M. Hitt. "Information Technology, Work Organizational and the Demand for Skilled Labor: Firm-level Evidence." Quarterly Journal of Economics 117 (2002): 339-76.

[11] Brynjolfsson, Erik, and Lorin M. Hitt. "Information Technology as a Factor of Production: The Role of Differences Among Firms." Economics of Innovation and New Technology 3, no. 4 (1995): 183-200.

[12] Brynjolfsson, Erik, and Lorin M. Hitt. "Paradox Lost? Firm-level Evidence on the returns to information systems spending." Management Science 42, no. 4 (1996): $541-48$.

[13] Brynjolfsson, Erik, and Lorin M. Hitt. "Computing Productivity: Firm-Level Evidence." Review of Economics and Statistics 85, no. 4 (2003): 793-808.

[14] Brynjolfsson, Erik, Lorin M. Hitt, and Shinkyu Yang. "Intangible Assets: Computers and Organizational Capital." Brookings Papers on Economic Activity 2002, no. 1 (2002): 137-82. 
[15] Census Bureau. "Annual Capital Expenditures, 1998." Available online at: http://www.census.gov/csd/ace/.

[16] Chirinko, Robert S. "Multiple Capital Inputs, Q, and Investment Spending." Journal of Economic Dynamics and Control 17 (1993): 907-28.

[17] Cummins, Jason and Matthew Dey. "Taxation, Investment, and Firm Growth with Heterogeneous Capital." Mimeo, University of Chicago (1998). Available online at: http://home.uchicago.edu/ ${ }^{\sim}$ mdey/cdes.pdf

[18] Cummins, Jason, Kevin A. Hassett, and R. Glenn Hubbard. "A Reconsideration of Investment Behavior using Tax Reforms as Natural Experiments." Brookings Papers on Economic Activity 1994, no. 2 (1994): 1-74.

[19] Doms, Mark E., and Timothy Dunne. "Capital Adjustment Patterns in Manufacturing Plants." Review of Economic Dynamics 1, no. 2 (1998): 409-29.

[20] Ellison, Glenn, and Edward L. Glaeser. 1997. "Geographic Concentration in U.S. Manufacturing Industries: A Dartboard Approach." Journal of Political Economy 105(5) (October) pp.889-927.

[21] Ellison, Glenn, and Edward L. Glaeser. 1999. "The Geographic Concentration of U.S. Industry: Does Natural Advantage Explain Agglomeration." American Economic Review 89(2) (May) pp. 311-316.

[22] Fisher, Franklin M. "Embodied Technical Change and the Existence of an Aggregate Capital Stock." Review of Economic Studies 32 (1965): 263-88.

[23] Gilchrist, Simon, Vijay Gurbaxani, and Robert Town. "Productivity and the PC Revolution." Mimeo (2003).

[24] Goolsbee, Austan. "Taxes And The Quality Of Capital." Journal of Public Economics 88, no. 3-4 (2004): 519-43.

[25] Gordon, Robert. "Does the 'New Economy' Measure Up to the Great Inventions of the Past?" Journal of Economic Perspectives 14, no. 4 (2000): 49-74.

[26] Greenan, Nathalie, and Jacques Mairesse. "Computers and Productivity in France: Some Evidence." Economics of Innovation and New Technology 9, no. 3 (2000): $275-315$. 
[27] Griliches, Zvi, and Donald Siegel. "Purchased Services, Outsourcing, Computers, and Productivity in Manufacturing." Output Measurement in the Service Sectors, National Bureau of Economic Research Studies in Income and Wealth. Editors Ernst R. Berndt, Timothy F. Bresnahan, and Marilyn E. Manser. Vol. 56. Chicago and London: University of Chicago Press, 1992.

[28] Jorgenson, Dale W. "Capital Theory and Investment Behavior." American Economic Review 53: pp. 366-78.

[29] Jorgenson, Dale W, and Kevin J. Stiroh. "Raising the Speed Limit: U.S. Economic Growth in the Information Age." Brookings Papers on Economic Activity 2000, no. 1 (2000): 125-212.

[30] Lev, Baruch, and Suresh Radhakrishnan. "The Measurement Of Firm-Specific Organization Capital.” NBER Working Paper 9581 (2003).

[31] Oliner, Stephen D., and Daniel E. Sichel. "Computers and Output Growth Revisited: How Big Is the Puzzle?" Brookings Papers on Economic Activity 2 (1994): $273-317$.

[32] Oliner, Stephen D., and Daniel E. Sichel. "The Resurgence of Growth in the Late 1990s: Is Information Technology the Story?" Journal of Economic Perspectives 14, no. 4 (2000): 3-22.

[33] Olley, Steven G. and Ariel Pakes. "The Dynamics of Productivity in the Telecommunications Equipment Industry." Econometrica 64, no. 4 (1996): 1263-97.

[34] Solow, Robert M. "The Production Function and The Theory of Capital." Review of Economic Studies 23, no. 2 (1955-1956): 101-8.

[35] Stiroh, Kevin. "Are ICT Spillovers Driving the New Economy." Review of Income and Wealth 48, no. 1 (2002): 33-57.

[36] Stiroh, Kevin. "Reassessing the Impact of IT in the Production Function: A MetaAnalysis." Paper presented at the NBER/CRIW/CREST Conference on R\&D, Education, and Productivity in honor of Zvi Griliches, August 2003.

[37] Syverson, Chad. "Using Market Segmentation to Obtain Plant-Specific Instruments: A Practical Application." Mimeo, University of Maryland (1999). 
[38] Wilson, Daniel J. "Is Embodied Technology the Result of Upstream R\&D? Industry-Level Evidence." Review of Economic Dynamics 5 (2002): 285-317.

[39] Wilson, Daniel J. "Investment Behavior of U.S. Firms over Heterogeneous Capital Goods." Mimeo, Federal Reserve Bank of San Francisco (2004).

\section{Appendix A - Variable construction}

The following is a list of the key variables used in this paper and how they were constructed from the data at hand:

Real Output - Real Output is obtained by dividing Compustat's sales variable (SALES_NET - \#A12) by the BEA's 3-digit SIC level gross output deflator (P): Y $=$ SALES_NET $/$ P.

Total capital - Total capital (K) is obtained by multiplying Compustat's Property, Plant, and Equipment (Total - Gross) (PPEGT) by the 2-digit industry ratio of capital services to book value of capital. A preferable method for measuring the capital stock would have been the perpetual inventory method. However, the necessary long time series of past annual investment is not available. Fortunately, it has been shown that the book value capital stock yields virtually identical results in production function regressions to perpetual inventory capital stock. ${ }^{45}$

Labor - The labor input (L) is measured as the number of employees (EMP) reported in Compustat.

Wages and Labor Costs - For a subset of firms, Compustat provides data on Labor and Related Expenses (XLR). For these firms, the average wage can be obtained by dividing XLR by EMP. For firms with missing values for XLR, I impute the average wage by multiplying the firm's number of employees (EMP) by the 3-digit industry mean of average wages, computed over firms with nonmissing values for XLR. If there 2 or fewer firms with nonmissing XLR in that 3-digit industry, I use the 2-digit industry mean. XLR for firms with missing values is then imputed by taking the product of the imputed average wage and the reported value of EMP.

Nominal Materials Costs - Nominal materials (PM) are calculated (using Compustat) as sales net of Operating Income Before Depreciation (OIDBP) and Labor and Related Expenses (XLR):

\footnotetext{
${ }^{45}$ See Becker, Haltiwanger, Jarmin, Klimek, and Wilson (2004).
} 
$\mathrm{PM}=\mathrm{SALES} \_\mathrm{NET}-\mathrm{OIDBP}-\mathrm{XLR}$.

An equivalent definition is Cost of Goods Sold (COGS) plus Selling, General, and Administrative Expense (XSGA) minus XLR:

$\mathrm{PM}=\mathrm{COGS}+\mathrm{XSGA}-\mathrm{wL}$.

The two definitions are equivalent since OIDBP is defined as SALES_NETCOGS-XSGA. I use the first definition unless it yields a missing value in which case I use the second definition.

Real Materials Costs - Real materials costs (M) are calculated as nominal materials (PM) deflated by the BEA's 3-digit gross output deflator (P). Unfortunately, no separate deflator exists that is specific to materials.

2-factor productivity - The natural log of 2-factor productivity (2FP), which is the dependent variable in the $2 \mathrm{FP}$ regressions, is computed using the following formula:

$$
2 F P=y-\left(\frac{r K}{P Y}\right) k-\left(\frac{w L}{P Y}\right) \ell
$$

where $y, k$, and $\ell$ are the logs of real output $(\mathrm{Y})$, total capital $(\mathrm{K})$, and labor $(\mathrm{L})$ (all defined above). $\quad r$ is the capital rental price, obtained at the 2-digit SIC level from the BLS. $w L$ comes from Compustat's variable, Labor and Related Expenses (XLR). As discussed in Section 3, as a robustness check, I also use an alternative measure of $2 \mathrm{FP}$ where $\mathrm{Y}$ is replaced by double-deflated value added (VA): $\mathrm{VA}=\mathrm{Y}-\mathrm{M}$.

3-factor productivity - Similar to $2 F P$, the natural log of 3-factor productivity $(3 \mathrm{FP})$ is computed as:

$$
3 F P=y-\left(\frac{r K}{P Y}\right) k-\left(\frac{w L}{P Y}\right) \ell-\left(\frac{P M}{P Y}\right) m
$$

where $y, k, \ell$ and $m$ are the natural logs of output, capital, labor, and materials, respectively.

Investment Spike - The investment spike dummy variable (SPIKE) is 1 if current total investment is equal to or greater than $20 \%$ of $\mathrm{K}$; 0 otherwise.

Employment Size - The employment size class indicator (SIZE) can take on five values:

$$
\begin{aligned}
& \mathrm{SIZE}=1 \text { if } \mathrm{L}<1000 \\
& \mathrm{SIZE}=2 \text { if } 1000 \leq \mathrm{L}<2000 \\
& \mathrm{SIZE}=3 \text { if } 2000 \leq \mathrm{L}<4500
\end{aligned}
$$


$\mathrm{SIZE}=4$ if $4500 \leq \mathrm{L}<11500$

$\mathrm{SIZE}=5$ if $11500 \leq \mathrm{L}$ 
Figure 1. Time Path of Production Function Regression Coefficients

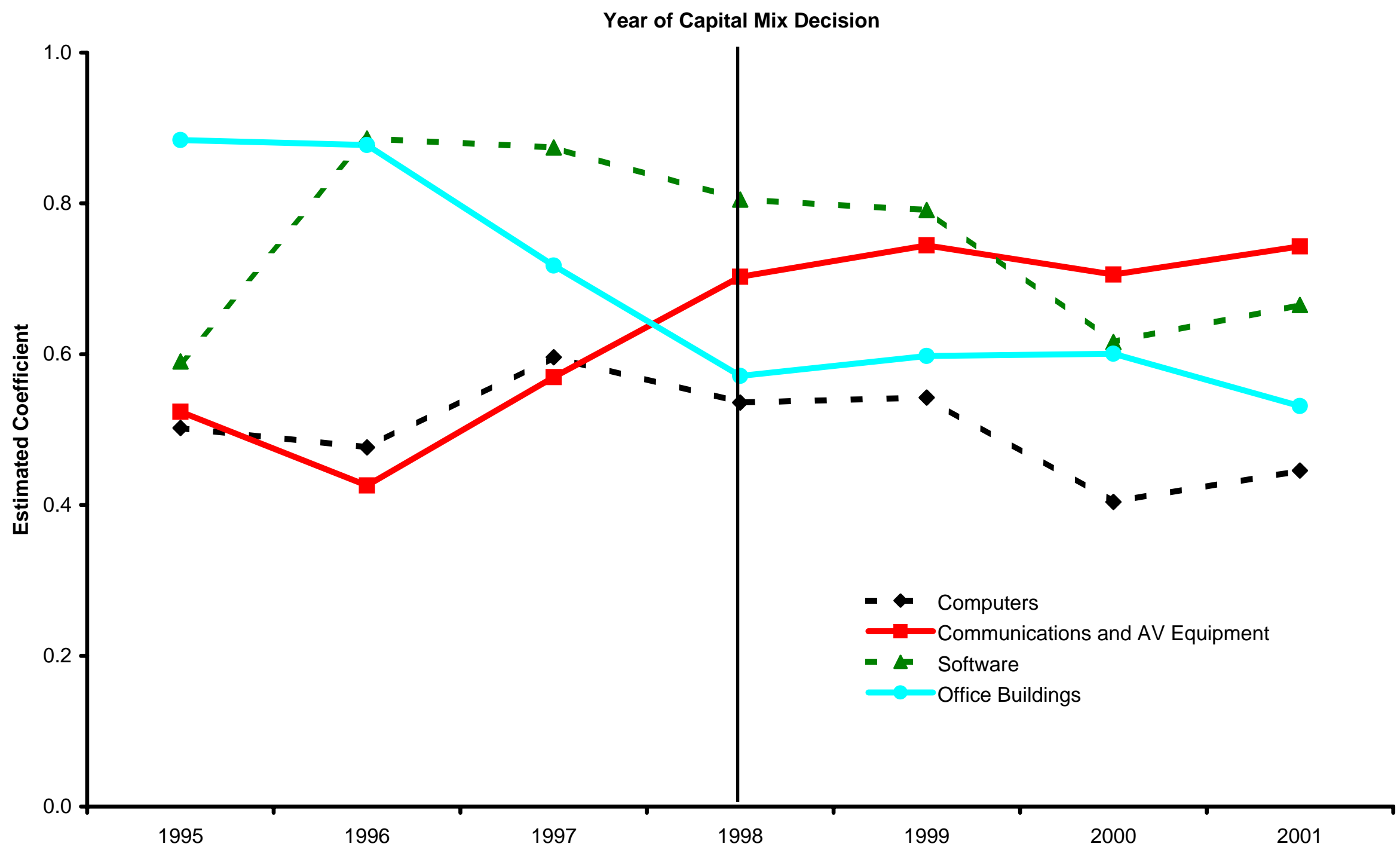


Figure 2 -- Implied Marginal Products and BLS Rental Prices

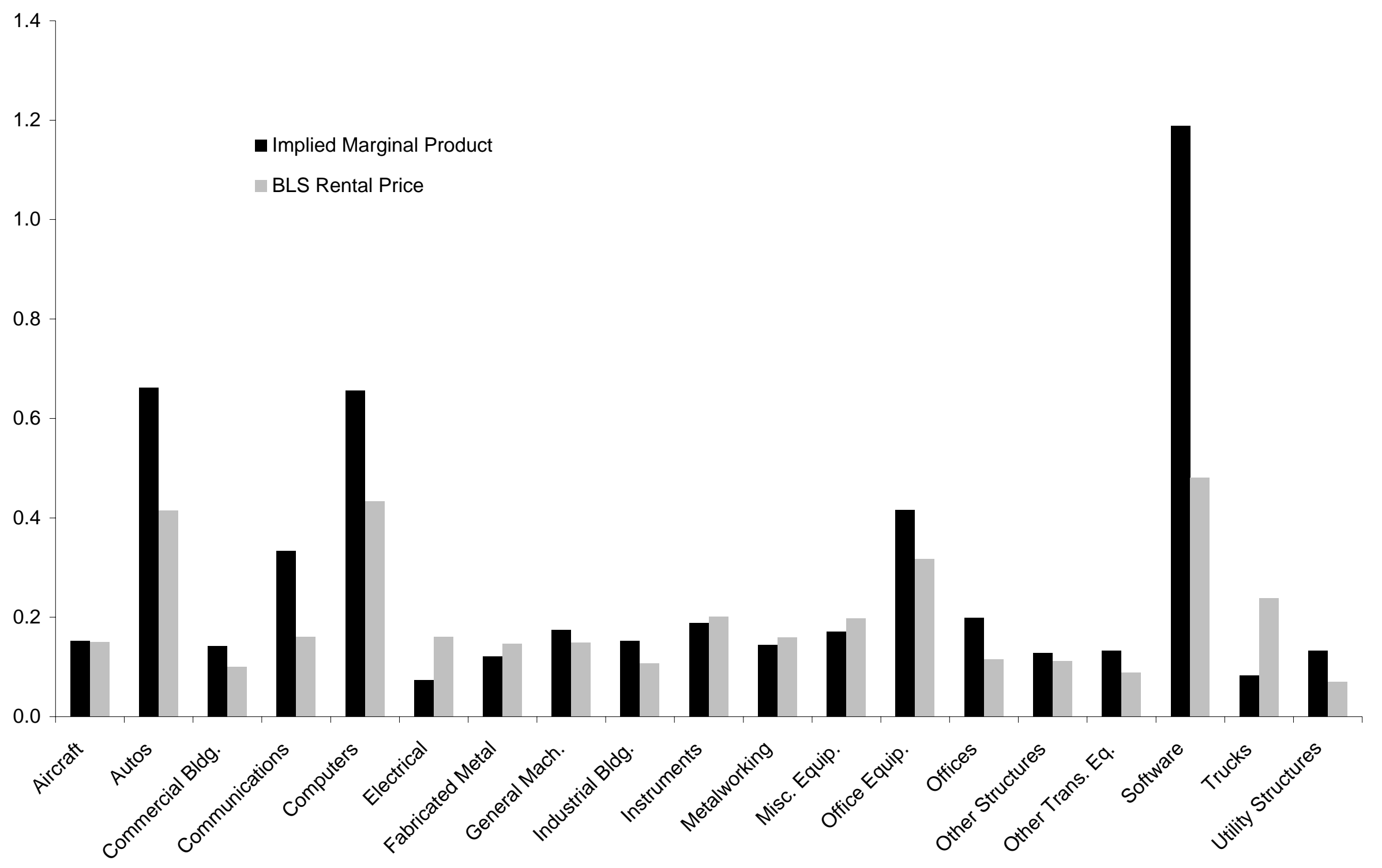


TABLE 1. ACES asset types and aggregated categories used in regressions

\begin{tabular}{|c|c|c|}
\hline Original ACES Asset Type Codes & Description & Aggregated Category Names \\
\hline \multicolumn{3}{|c|}{ Equipment } \\
\hline 311 & Computer and Peripheral Equipment & Computers \\
\hline 312 & Office Equipment Except Computers and Peripherals & Office Equipment \\
\hline 313 & Communications, Audio, and Video Equipment & Communications and AV Equipmen \\
\hline 314 & Navigational, Measuring, Electromedical, and Control Instruments & \\
\hline 315 & Medical Equipment and Supplies & Instruments \\
\hline 316 & Capitalized Software Purchased Separately & Software \\
\hline 321 & Fabricated Metal Products & Fabricated Metal Products \\
\hline 322 & Metalworking Machinery & Metalworking Machinery \\
\hline 323 & Special Industrial Machinery & Special Industrial Machinery \\
\hline 324 & $\begin{array}{l}\text { Ventilation, Heating, Air-Conditioning, Commercial Refrigeration, and } \\
\text { Other General Purpose Machinery }\end{array}$ & General Purpose Machinery \\
\hline 331 & Cars and Light Trucks & Autos \\
\hline 332 & Heavy Duty Trucks & Trucks \\
\hline 333 & Aerospace Products and Parts & Aircraft \\
\hline 334 & Other Transportation Equipment & Other Transportation Equipment \\
\hline 341 & Engine, Turbine, and Power Transmission Equipment & \\
\hline 342 & Electrical Transmission and Distribution Equipment & Electrical Equipment \\
\hline 343 & Electrical Equipment, NEC & \\
\hline 344 & Mining and Oil and Gas Field Machinery and Equipment & \\
\hline 345 & Floating Oil and Gas Drilling and Production Platforms & \\
\hline 346 & Nuclear Fuel & \\
\hline 351 & Furniture and Related Products & \\
\hline 352 & Agricultural Equipment & Miscellaneous Equipment \\
\hline 353 & Construction Machinery & \\
\hline 354 & Service Industry Equipment & \\
\hline 355 & Other Miscellaneous Equipment & \\
\hline 361 & Artwork, Books, and Other Equipment, NEC & \\
\hline
\end{tabular}




\begin{tabular}{|c|c|c|}
\hline \multicolumn{3}{|c|}{$\begin{array}{c}\text { TABLE } 1 \text { continued... } \\
\text { Structures }\end{array}$} \\
\hline 131 & Manufacturing, Processing, and Assembly Plants & \multirow{2}{*}{ Industrial Buildings } \\
\hline 132 & Industrial Nonbuilding Structures & \\
\hline 141 & Office, Bank, and Professional Buildings & \multirow{2}{*}{ Offices } \\
\hline 142 & Medical Offices & \\
\hline 151 & Automotive Facilities & \multirow{8}{*}{ Commercial Buildings } \\
\hline 152 & Stores - Food Related & \\
\hline 153 & Multi-Retail Stores & \\
\hline 154 & Warehouses and Distribution Centers (except Passenger) & \\
\hline 155 & Other Commercial Stores/Buildings, NEC & \\
\hline 161 & Hospitals & \\
\hline 162 & Special Care Facilities & \\
\hline 171 & Amusement and Recreational Facilities & \\
\hline 181 & Air, Land, and Water Transportation Facilities & \multirow{4}{*}{ Utility Structures } \\
\hline 191 & Telecommunication Facilities & \\
\hline 192 & Electric, Nuclear, and Other Power Facilities & \\
\hline 193 & Water Supply, Sewage, and Waste Disposal Facilities & \\
\hline 111 & Residential Structures & \multirow{13}{*}{ Other Structures } \\
\hline 112 & Manufactured (Mobile) Homes & \\
\hline 121 & Hotels, Motels, and Inns & \\
\hline 201 & Preschool, Primary/Secondary, and Higher Education Facilities & \\
\hline 202 & Special School and Other Educational Facilities & \\
\hline 203 & Religious Buildings & \\
\hline 204 & Public Safety Buildings & \\
\hline 211 & Mine Shafts & \\
\hline 212 & Petroleum and Natural Gas Wells & \\
\hline 213 & Other Mining and Well Construction & \\
\hline 221 & Conservation and Control Structures & \\
\hline 222 & Highway and Street Structures & \\
\hline 223 & Other Non-building Structures, NEC & \\
\hline
\end{tabular}


Table 2 -- Summary Statistics

\begin{tabular}{|c|c|c|c|}
\hline Variable & Mean & Standard Deviation & Correlation with Sales $^{1}$ \\
\hline Sales & 2344 & 7499 & - \\
\hline K & 2377 & 9055 & 0.796 \\
\hline $\mathrm{L}$ & 12.471 & 38.810 & 0.714 \\
\hline Spike & 0.316 & 0.465 & -0.025 \\
\hline Size Class1 & 0.159 & 0.222 & -0.125 \\
\hline Size Class2 & 0.193 & 0.395 & -0.130 \\
\hline Size Class3 & 0.221 & 0.415 & -0.119 \\
\hline Size Class 4 & 0.212 & 0.409 & -0.053 \\
\hline Size Class5 & 0.215 & 0.411 & 0.409 \\
\hline Computer and Peripheral Equipment & 0.155 & 0.222 & -0.011 \\
\hline Office Equipment Except Computers and Peripherals & 0.019 & 0.070 & -0.011 \\
\hline Communications, Audio, and Video Equipment & 0.030 & 0.119 & 0.028 \\
\hline Capitalized Software Purchased Separately & 0.036 & 0.099 & -0.044 \\
\hline Fabricated Metal Products & 0.014 & 0.083 & -0.023 \\
\hline Metalworking Machinery & 0.065 & 0.187 & -0.037 \\
\hline Special Industrial Machinery & 0.156 & 0.276 & -0.025 \\
\hline General Purpose Machinery & 0.046 & 0.140 & -0.009 \\
\hline Cars and Light Trucks & 0.015 & 0.074 & 0.258 \\
\hline Heavy Duty Trucks & 0.011 & 0.074 & -0.015 \\
\hline Aerospace Products and Parts & 0.011 & 0.087 & 0.380 \\
\hline Other Transportation Equipment & 0.015 & 0.084 & -0.011 \\
\hline Industrial Equipment & 0.088 & 0.192 & 0.217 \\
\hline Office Buildings & 0.035 & 0.146 & -0.023 \\
\hline Commercial Buildings & 0.027 & 0.129 & 0.020 \\
\hline Utilities & 0.018 & 0.088 & 0.002 \\
\hline Other Structures & 0.021 & 0.112 & 0.006 \\
\hline Instruments & 0.080 & 0.141 & -0.023 \\
\hline Electrical Equipment & 0.049 & 0.119 & 0.015 \\
\hline Miscellaneous Equipment & 0.108 & 0.195 & -0.021 \\
\hline Number of Equipment Types & 4.563 & 3.136 & - \\
\hline Number of Structure Types & 1.655 & 1.167 & - \\
\hline Number of Observations & 1650 & & \\
\hline
\end{tabular}

'Partial correlations controlling for 3-digit SIC industry dummy variables. 
Table 3 -- Production Function Regressions

\begin{tabular}{|c|c|c|c|c|c|c|c|c|c|c|c|}
\hline & \multicolumn{3}{|c|}{$\begin{array}{c}(1) \\
1998\end{array}$} & \multicolumn{3}{|c|}{$\begin{array}{c}(2) \\
1999\end{array}$} & \multicolumn{3}{|c|}{$\begin{array}{c}(3) \\
2000\end{array}$} & \multicolumn{2}{|c|}{$\begin{array}{c}(4) \\
2001\end{array}$} \\
\hline $\begin{array}{l}\text { Variable } \\
\text { Investment Shares: }\end{array}$ & Coet & Estimate & & Coef. & Estimate & & Coef. & Estimate & & Coef. & Estimate \\
\hline Aircraft & 0.03 & $(0.15)$ & & -0.22 & $(0.20)$ & & -0.30 & $(0.22)$ & & -0.20 & $(0.22)$ \\
\hline Autos & 0.48 & $(0.32)$ & & 0.42 & $(0.41)$ & & 0.47 & (0.39) & & 0.57 & $(0.37)$ \\
\hline Commercial Buildings & -0.06 & $(0.14)$ & & -0.13 & $(0.15)$ & & -0.28 & $(0.16)$ & * & -0.22 & $(0.15)$ \\
\hline Communications and AV Equipment & 0.70 & $(0.26)$ & *** & 0.74 & $(0.23)$ & *** & 0.71 & $(0.21)$ & *** & 0.74 & $(0.27)^{\star \star \star}$ \\
\hline Computers & 0.54 & $(0.10)$ & *** & 0.54 & $(0.11)$ & *** & 0.40 & $(0.12)$ & *** & 0.45 & $(0.12)^{* \star *}$ \\
\hline Electrical Equipment & -0.23 & $(0.17)$ & & -0.15 & $(0.19)$ & & -0.09 & $(0.18)$ & & 0.12 & $(0.19)$ \\
\hline Fabricated Metal Products & -0.10 & $(0.12)$ & & -0.03 & $(0.14)$ & & -0.06 & $(0.17)$ & & -0.04 & $(0.15)$ \\
\hline General Purpose Machinery & 0.11 & $(0.09)$ & & 0.14 & $(0.09)$ & & 0.20 & $(0.12)$ & * & 0.28 & $(0.12) * \star$ \\
\hline Industrial Buildings & 0.11 & $(0.11)$ & & 0.22 & $(0.11)$ & * & 0.15 & $(0.13)$ & & 0.18 & $(0.13)$ \\
\hline Instruments & 0.10 & $(0.17)$ & & 0.06 & $(0.17)$ & & -0.07 & $(0.19)$ & & -0.08 & $(0.18)$ \\
\hline Metalworking Machinery & 0.00 & $(0.08)$ & & -0.01 & $(0.09)$ & & -0.04 & $(0.09)$ & & -0.06 & $(0.09)$ \\
\hline Miscellaneous Equipment & 0.06 & $(0.10)$ & & 0.10 & $(0.10)$ & & 0.01 & $(0.11)$ & & 0.08 & $(0.10)$ \\
\hline Office Equipment & 0.30 & $(0.22)$ & & 0.18 & $(0.23)$ & & 0.14 & $(0.25)$ & & 0.10 & $(0.26)$ \\
\hline Offices & 0.57 & $(0.15)$ & *** & 0.60 & $(0.16)$ & *** & 0.60 & $(0.18)$ & . & 0.53 & $(0.19) * * *$ \\
\hline Other Structures & -0.12 & $(0.16)$ & & 0.15 & $(0.17)$ & & -0.19 & $(0.23)$ & & 0.23 & $(0.21)$ \\
\hline Other Transportation Equipment & -0.07 & $(0.21)$ & & -0.26 & $(0.24)$ & & -0.05 & $(0.26)$ & & 0.05 & $(0.25)$ \\
\hline Software & 0.81 & $(0.19)$ & *** & 0.79 & $(0.21)$ & *** & 0.62 & (0.19) & *** & 0.67 & $(0.19)^{* \star *}$ \\
\hline Trucks & -0.13 & $(0.22)$ & & -0.02 & $(0.28)$ & & -0.14 & $(0.26)$ & & -0.08 & $(0.25)$ \\
\hline $\begin{array}{l}\text { Utility Structures } \\
\text { Other Variables: }\end{array}$ & -0.17 & $(0.22)$ & & -0.03 & $(0.18)$ & & 0.17 & $(0.17)$ & & 0.33 & $(0.17)$ * \\
\hline $\log (k)$ & 0.42 & $(0.02)$ & *** & 0.43 & $(0.02)$ & *** & 0.41 & $(0.03)$ & *** & 0.42 & $(0.02) * * \star$ \\
\hline $\log (e m p)$ & 0.53 & $(0.04)$ & *** & 0.54 & $(0.04)$ & *** & 0.59 & $(0.05)$ & $* \star *$ & 0.53 & $(0.05)^{* * *}$ \\
\hline Size Class2 & -0.06 & $(0.06)$ & & -0.05 & $(0.06)$ & & -0.11 & $(0.07)$ & & -0.05 & $(0.07)$ \\
\hline Size Class3 & -0.01 & $(0.07)$ & & 0.00 & $(0.07)$ & & -0.07 & $(0.08)$ & & 0.00 & $(0.08)$ \\
\hline Size Class4 & -0.06 & (0.09) & & -0.04 & $(0.09)$ & & -0.09 & (0.09) & & -0.01 & $(0.11)$ \\
\hline Size Class5 & 0.01 & (0.13) & & -0.05 & $(0.14)$ & & -0.13 & $(0.14)$ & & 0.00 & $(0.16)$ \\
\hline Spike dummy & 0.05 & $(0.04)$ & & 0.06 & $(0.04)$ & * & 0.07 & $(0.04)$ & * & 0.04 & $(0.04)$ \\
\hline Constant & 3.35 & $(0.16)$ & *** & 1.87 & $(0.24)$ & *** & 3.26 & $(0.26)$ & & 3.07 & $(0.21)^{* * *}$ \\
\hline Number of Observations & 1651 & & & 1502 & & & 1374 & & & 1335 & \\
\hline $\mathrm{R}-\mathrm{Sq}$ & 0.8959 & & & 0.8957 & & & 0.8977 & & & 0.9049 & \\
\hline
\end{tabular}

Notes: These regressions also include 3-digit SIC industry dummies and state dummies, though due to confidentiality concerns, the coefficients on these dummies are not shown.

Robust standard errors are shown in parentheses.

*** denotes significance at the $99 \%$ level

** denotes significance at the $95 \%$ level

${ }^{*}$ denotes significance at the $90 \%$ level 
Table 4 -- Labor Productivity Regressions

\begin{tabular}{|c|c|c|c|c|c|c|c|c|}
\hline & \multicolumn{2}{|c|}{$\begin{array}{c}(1) \\
1998\end{array}$} & \multicolumn{2}{|c|}{$\begin{array}{c}(2) \\
1999 \\
\end{array}$} & \multicolumn{2}{|c|}{$\begin{array}{c}(3) \\
2000 \\
\end{array}$} & \multicolumn{2}{|c|}{$\begin{array}{c}(4) \\
2001\end{array}$} \\
\hline Investment Shares: & Coef. & stimate & Coef. E & stimate & Coef. E & timate & Coef. & stimate \\
\hline Aircraft & -0.01 & $(0.14)$ & -0.25 & $(0.19)$ & -0.34 & $(0.21)$ & -0.26 & $(0.21)$ \\
\hline Autos & 0.43 & $(0.33)$ & 0.37 & $(0.40)$ & 0.45 & $(0.38)$ & 0.50 & $(0.37)$ \\
\hline Commercial Buildings & -0.06 & $(0.14)$ & -0.12 & $(0.15)$ & -0.27 & $(0.16) *$ & -0.21 & $(0.15)$ \\
\hline Communications and AV Equipment & 0.71 & $(0.26)^{* \star *}$ & 0.75 & $(0.23)^{* * *}$ & 0.68 & $(0.22) * * *$ & 0.69 & $(0.29) * *$ \\
\hline Computers & 0.56 & $(0.10)^{* \star *}$ & 0.58 & $(0.11)^{* * *}$ & 0.42 & $(0.12)^{* \star *}$ & 0.44 & $(0.12)^{* * *}$ \\
\hline Electrical Equipment & -0.24 & $(0.18)$ & -0.15 & $(0.19)$ & -0.09 & $(0.19)$ & 0.15 & $(0.20)$ \\
\hline Fabricated Metal Products & -0.11 & $(0.13)$ & -0.02 & $(0.14)$ & 0.01 & $(0.17)$ & -0.02 & $(0.17)$ \\
\hline General Purpose Machinery & 0.12 & $(0.09)$ & 0.15 & $(0.09)$ & 0.22 & $(0.12)$ * & 0.30 & $(0.13)$ ** \\
\hline Industrial Buildings & 0.12 & $(0.11)$ & 0.23 & $(0.11) * *$ & 0.16 & $(0.13)$ & 0.17 & $(0.13)$ \\
\hline Instruments & 0.11 & $(0.17)$ & 0.08 & $(0.16)$ & -0.05 & $(0.20)$ & -0.02 & $(0.19)$ \\
\hline Metalworking Machinery & 0.04 & $(0.08)$ & 0.05 & $(0.09)$ & 0.02 & $(0.09)$ & 0.00 & $(0.09)$ \\
\hline Miscellaneous Equipment & 0.02 & $(0.10)$ & 0.06 & $(0.10)$ & -0.05 & $(0.11)$ & 0.03 & $(0.11)$ \\
\hline Office Equipment & 0.30 & $(0.23)$ & 0.18 & $(0.24)$ & 0.10 & $(0.26)$ & 0.05 & $(0.28)$ \\
\hline Offices & 0.58 & $(0.16)^{* * *}$ & 0.59 & $(0.16)^{* * *}$ & 0.57 & $(0.19)^{* * *}$ & 0.48 & $(0.19)$ ** \\
\hline Other Structures & -0.13 & $(0.16)$ & 0.12 & $(0.16)$ & -0.30 & $(0.23)$ & 0.11 & $(0.23)$ \\
\hline Other Transportation Equipment & -0.09 & $(0.20)$ & -0.25 & $(0.24)$ & -0.05 & $(0.26)$ & 0.06 & $(0.25)$ \\
\hline Software & 0.81 & $(0.20) * * *$ & 0.80 & $(0.21) * * *$ & 0.61 & $(0.19) * * *$ & 0.65 & $(0.19) * * *$ \\
\hline Trucks & -0.13 & $(0.22)$ & -0.04 & $(0.28)$ & -0.15 & $(0.26)$ & -0.09 & $(0.25)$ \\
\hline $\begin{array}{l}\text { Utility Structures } \\
\text { Other Variables: }\end{array}$ & -0.22 & $(0.23)$ & -0.09 & $(0.18)$ & 0.08 & $(0.17)$ & 0.24 & $(0.18)$ \\
\hline Capital-Labor ratio & 0.43 & $(0.02) * * *$ & 0.44 & $(0.02) * * *$ & 0.42 & $(0.03) * * *$ & 0.43 & $(0.03) * * *$ \\
\hline Size Class2 & -0.11 & $(0.06) * *$ & -0.09 & $(0.06)$ & -0.06 & $(0.07)$ & -0.09 & $(0.06)$ \\
\hline Size Class3 & -0.11 & $(0.05)$ ** & 0.06 & $(0.09)$ & -0.05 & $(0.06)$ & -0.10 & $(0.06)$ \\
\hline Size Class4 & -0.19 & $(0.05) * * *$ & -0.11 & $(0.06) *$ & -0.09 & $(0.06)$ & -0.15 & $(0.06)$ ** \\
\hline Size Class5 & -0.25 & $(0.05)^{* * *}$ & -0.17 & $(0.06)^{* * *}$ & -0.16 & $(0.06)^{* * *}$ & -0.22 & $(0.06)^{* * *}$ \\
\hline Spike dummy & 0.05 & $(0.04)$ & 0.06 & $(0.04)$ & 0.02 & $(0.04)$ & 0.03 & $(0.04)$ \\
\hline Constant & 3.46 & $(0.16)^{* \star *}$ & 1.99 & $(0.24)^{* * *}$ & 3.50 & $(0.26)^{* * *}$ & 3.13 & $(0.21)^{* * *}$ \\
\hline $\begin{array}{l}\text { Number of Observations } \\
\mathrm{R}-\mathrm{Sq}\end{array}$ & $\begin{aligned} & 1636 \\
& 0.6433\end{aligned}$ & & $\begin{array}{r}1489 \\
0.6466\end{array}$ & & $\begin{array}{r}1360 \\
0.6345\end{array}$ & & $\begin{array}{r}1322 \\
0.6464\end{array}$ & \\
\hline
\end{tabular}

Notes: These regressions also include 3-digit SIC industry dummies and state dummies, though due to confidentiality concerns, the coefficients on these dummies are not shown.

Robust standard errors are shown in parentheses.

$* * *$ denotes significance at the $99 \%$ level

** denotes significance at the $95 \%$ level

${ }^{*}$ denotes significance at the $90 \%$ level 
Table 5 -- 2FP Regressions

\begin{tabular}{|c|c|c|c|c|c|}
\hline & $\begin{array}{c}(1) \\
1998\end{array}$ & $\begin{array}{c}(2) \\
1999\end{array}$ & $\begin{array}{c}(3) \\
2000\end{array}$ & & 4) \\
\hline $\begin{array}{l}\text { Variable } \\
\text { Investment Shares: }\end{array}$ & $\underline{\text { Coef. Estimate }}$ & Coef. Estimate & $\underline{\text { Coef. Estimate }}$ & Coef. & Estimate \\
\hline Aircraft & $0.54 \quad(1.46)$ & $(1.47)$ & $(1.24)$ & -0.47 & $(1.30)$ \\
\hline Autos & $-1.05 \quad(1.33)$ & $(1.43)$ & $-1.72(1.61)$ & -2.65 & (1.63) \\
\hline Commercial Buildings & $(0.66)$ & $(0.47)$ & $-0.70 \quad(0.64)$ & -1.48 & $(0.66)^{* *}$ \\
\hline Communications and AV Equipment & $(1.24)$ & $(0.87)^{* * *}$ & $2.54(0.90)^{* * *}$ & -0.41 & (1.98) \\
\hline Computers & $1.86(0.75) * \star$ & $(0.48) * * *$ & $(0.77)$ & 0.13 & $(0.59)$ \\
\hline Electrical Equipment & $(0.95)$ & $(0.95)$ & $(1.26)$ & -1.28 & (1.21) \\
\hline Fabricated Metal Products & $(0.57)^{* * *}$ & $(0.60)^{* * *}$ & $(0.75)$ & 0.82 & $(0.87)$ \\
\hline General Purpose Machinery & $(0.56)$ & $(0.55)^{*}$ & $(0.66)$ & -0.88 & (1.08) \\
\hline Industrial Buildings & $(0.60)$ & $(0.62)$ & $(1.04)$ & 0.33 & $(0.77)$ \\
\hline Instruments & $(0.68)$ & $(0.83)$ & $(1.46)$ & 0.06 & (1.06) \\
\hline Metalworking Machinery & $(0.37) * *$ & $(0.45) * *$ & $(0.45)$ & -0.32 & $(0.43)$ \\
\hline Miscellaneous Equipment & $(1.01)$ & $(0.51)$ & $(0.52)$ & -0.97 & $(0.78)$ \\
\hline Office Equipment & $(0.97) * *$ & $(1.00) * *$ & $(1.01)$ & 0.03 & $(0.70)$ \\
\hline Offices & $(0.88)$ & $(1.36)$ & (1.23) & 1.07 & $(0.73)$ \\
\hline Other Structures & $(2.49)$ * & $(1.27)$ & (2.39) & -1.69 & $(0.94)$ * \\
\hline Other Transportation Equipment & $(0.82)$ & $(1.09)$ & (1.08) & -1.83 & $(1.04)$ * \\
\hline Software & $(0.70)$ * & $(1.60)$ & (1.92) & 1.04 & $(0.73)$ \\
\hline Trucks & $(0.76)$ & $(0.78)$ & (1.42) & -1.98 & $(0.86)^{* *}$ \\
\hline $\begin{array}{l}\text { Utility Structures } \\
\text { Other Variables: }\end{array}$ & $(0.98)$ & $(1.11)$ & (1.67) & -1.51 & $(1.13)$ \\
\hline Size Class2 & $(0.46)$ & $(0.48)$ & $(0.54) * * *$ & 0.08 & $(0.41)$ \\
\hline Size Class3 & (0.31) & $(0.47)^{* *}$ & $(0.52)^{* * *}$ & 0.70 & $(0.24)^{* * *}$ \\
\hline Size Class4 & $(0.35)$ & $(0.45) * *$ & $(0.48)^{* * *}$ & 0.74 & $(0.27)^{* * *}$ \\
\hline Size Class5 & $(0.33) *$ & $(0.45)^{* *}$ & $(0.48) * * *$ & 1.11 & $(0.25)^{* * *}$ \\
\hline Spike dummy & $(0.21)^{* * *}$ & $(0.16)^{* * *}$ & $(0.20)^{* *}$ & 0.25 & $(0.14) *$ \\
\hline Constant & $(0.60)$ & $(1.04)$ & $(1.02)$ & 2.72 & $(0.93)^{* * *}$ \\
\hline $\begin{array}{l}\text { Number of Observations } \\
\mathrm{R}-\mathrm{Sq}\end{array}$ & $\begin{array}{r}1551 \\
0.2498\end{array}$ & $\begin{array}{r}1363 \\
0.2840\end{array}$ & $\begin{array}{r}1296 \\
0.2682\end{array}$ & $\begin{array}{r}1254 \\
0.2835\end{array}$ & \\
\hline
\end{tabular}

Notes: These regressions also include 3-digit SIC industry dummies and state dummies, though due to confidentiality concerns, the coefficients on these dummies are not shown.

Robust standard errors are shown in parentheses.

*** denotes significance at the $99 \%$ level

** denotes significance at the $95 \%$ level

* denotes significance at the $90 \%$ level 
Table 6 -- Marginal Products Implied by Estimated Coefficients (1998)

\begin{tabular}{|c|c|c|c|c|c|}
\hline & \multicolumn{3}{|c|}{ Implied Marginal Product } & & \\
\hline Capital Type & \begin{tabular}{c|} 
(1) \\
Production Function \\
\end{tabular} & $\begin{array}{c}(2) \\
\text { Labor Productivity } \\
\end{array}$ & $\begin{array}{c}(3) \\
2 \mathrm{FP} \\
\end{array}$ & $\begin{array}{l}\text { Official (BLS) rental } \\
\text { price/user cost }\end{array}$ & $\begin{array}{l}\text { Depreciation } \\
\text { rate }^{2} \\
\end{array}$ \\
\hline Aircraft & 0.15 & 0.13 & 0.30 & 0.15 & 0.08 \\
\hline Autos & 0.66 & 0.55 & -0.96 & 0.41 & 0.30 \\
\hline Commercial Buildings & $0.14^{* * *}$ & $0.14^{* * *}$ & $0.17^{\star \star \star}$ & 0.10 & 0.01 \\
\hline Communications and AV Equipment & $0.33^{* *}$ & $0.27 *$ & 0.58 & 0.16 & 0.08 \\
\hline Computers & $0.66^{* *}$ & $0.67^{* *}$ & $1.89 * * *$ & 0.43 & 0.27 \\
\hline Electrical Equipment & 0.07 & 0.09 & 0.08 & 0.16 & 0.09 \\
\hline Fabricated Metal Products & 0.12 & 0.14 & 0.50 & 0.15 & 0.07 \\
\hline General Purpose Machinery & 0.18 & 0.17 & 0.24 & 0.15 & 0.08 \\
\hline Industrial Buildings & $0.15^{* * *}$ & $0.16^{* * *}$ & 0.19 ** & 0.11 & 0.02 \\
\hline Instruments & 0.19 & 0.22 & 0.59 & 0.20 & 0.12 \\
\hline Metalworking Machinery & 0.14 & 0.17 & 0.40 & 0.16 & 0.09 \\
\hline Miscellaneous Equipment & 0.17 & 0.19 & -0.41 & 0.20 & 0.13 \\
\hline Office Equipment & 0.42 & 0.27 & 2.10 & 0.32 & 0.26 \\
\hline Offices & $0.20 * * *$ & $0.20^{* * *}$ & $0.28 * * *$ & 0.12 & 0.03 \\
\hline Other Structures & 0.13 & 0.13 & -0.49 & 0.11 & 0.04 \\
\hline Other Transportation Equipment & 0.13 & 0.14 & 0.17 & 0.09 & 0.04 \\
\hline Software & $1.19 * * \star$ & $1.37^{\star * *}$ & $1.82 * * *$ & 0.48 & 0.37 \\
\hline Trucks & 0.08 & 0.12 & 0.26 & 0.24 & 0.14 \\
\hline Utility Structures & $0.13^{* * *}$ & $0.14^{* * *}$ & 0.07 & 0.07 & 0.02 \\
\hline
\end{tabular}

${ }^{1}$ Calculated as: [(inv. share coefficient/capital elasticity $)^{\star}(B L S$ relative depreciation rate $\left.)+1\right]^{\star}(B L S$ rental price for Special Ind. Machinery). The BLS estimate of the user cost for Special Industry Machinery is 0.1449283 .

${ }^{2}$ The BLS estimate of the depreciation rate for total capital is 0.0980 .

Notes: These regressions also include 3-digit SIC industry dummies and state dummies, though due to confidentiality concerns, the coefficients on these dummies are not shown.

Asterisks indicate implied marginal product is significantly different than official (BLS) rental price (assuming only source of randomness in above formula comes from the inv. share coefficient).

*** denotes significance at the $99 \%$ level

** denotes significance at the $95 \%$ level

${ }^{*}$ denotes significance at the $90 \%$ level 
Table 7 -- Production Function Regression, Manufacturing vs. Non-Manufacturing

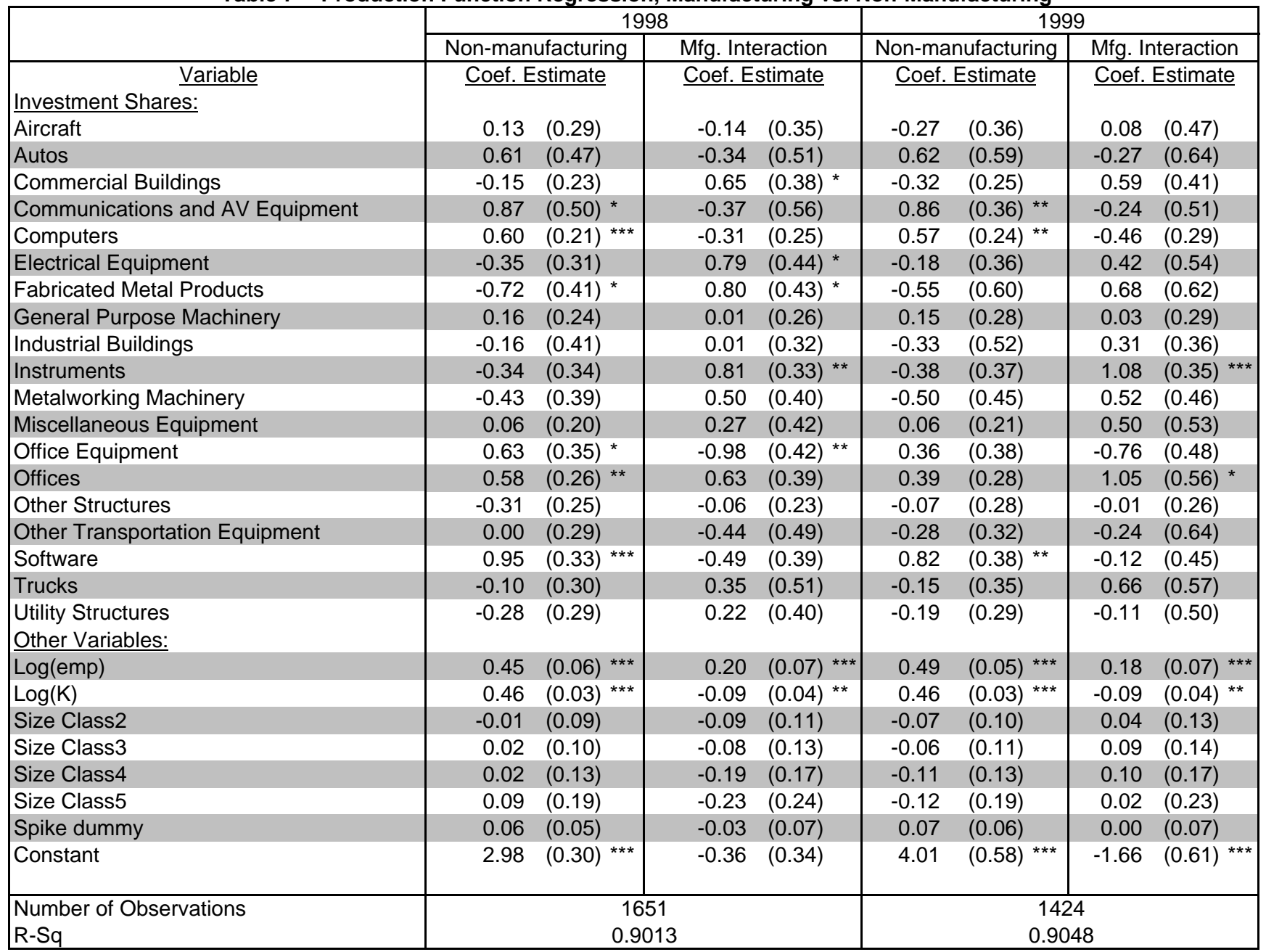

Robust standard errors are shown in parentheses. Coefficients on state and industry dummies are not shown.

$* * *$ denotes significance at the $99 \%$ level

${ }^{* *}$ denotes significance at the $95 \%$ level

* denotes significance at the $90 \%$ level 
Table 7 (continued) -- Production Function Regressions, Mfg. vs. Non-Mfg.

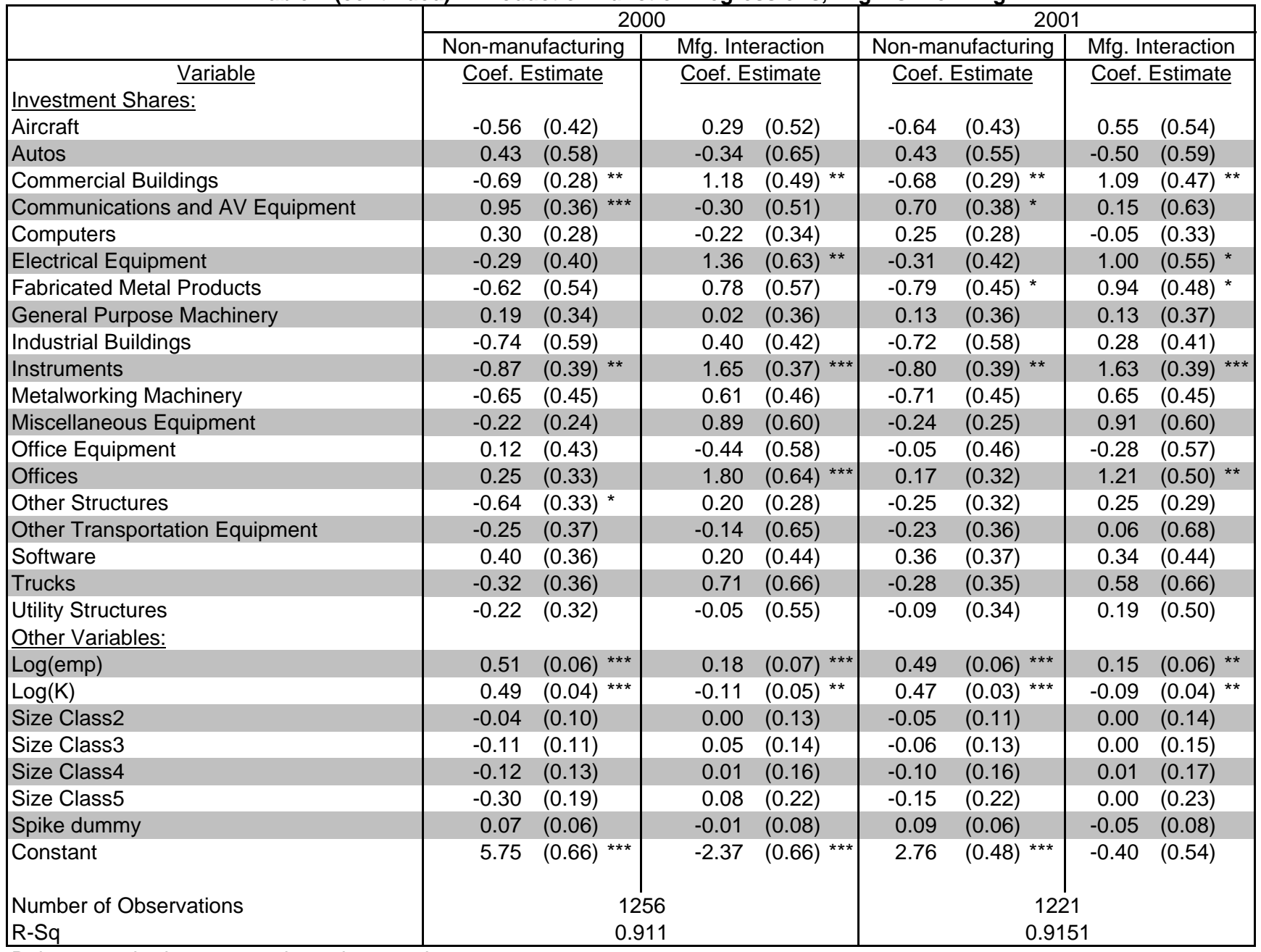

Robust standard errors are shown in parentheses.

*** denotes significance at the $99 \%$ level

** denotes significance at the $95 \%$ level

* denotes significance at the $90 \%$ level 
Table 8 -- Regressions using pre-estimated fixed effects

\begin{tabular}{|c|c|c|c|}
\hline & $\begin{array}{l}\text { 1995-1997 Fixed } \\
\text { Effect }\end{array}$ & $\begin{array}{l}\text { 1999-2001 Fixed } \\
\text { Effect }\end{array}$ & $\begin{array}{l}\text { Difference in Fixed Effects } \\
\text { (1999-2001 minus 1995-1997) }\end{array}$ \\
\hline Investment Shares: & $\underline{\text { Coef. Estimate }}$ & $\underline{\text { Coef. Estimate }}$ & Coef. Estimate \\
\hline Aircraft & $-0.05(0.09)$ & $-0.12(0.09)$ & $-0.13(0.07) *$ \\
\hline Autos & $0.02(0.15)$ & $0.25(0.29)$ & $0.30(0.27)$ \\
\hline Commercial Buildings & $-0.08(0.09)$ & $-0.10(0.08)$ & $0.05(0.05)$ \\
\hline Communications and AV Equipment & $0.28(0.12) * *$ & $0.35(0.18)$ * & $0.25(0.08)^{* \star \star}$ \\
\hline Computers & $0.23(0.08) * * *$ & $0.24(0.09) * * *$ & $0.08(0.05)$ \\
\hline Electrical Equipment & $0.04(0.07)$ & $-0.06(0.08)$ & $-0.07(0.05)$ \\
\hline Fabricated Metal Products & $-0.09(0.10)$ & $-0.03(0.12)$ & $0.16(0.06)$ ** \\
\hline General Purpose Machinery & $0.21(0.09) * *$ & $0.27(0.10) * * \star$ & $-0.05(0.05)$ \\
\hline Industrial Buildings & $0.17(0.09) *$ & $0.11(0.11)$ & $-0.06(0.06)$ \\
\hline Instruments & $0.04(0.13)$ & $-0.11(0.14)$ & $-0.01(0.08)$ \\
\hline Metalworking Machinery & $0.01(0.06)$ & $0.00(0.07)$ & $0.01(0.04)$ \\
\hline Miscellaneous Equipment & $0.01(0.06)$ & $0.00(0.07)$ & $-0.01(0.04)$ \\
\hline Office Equipment & $0.09(0.18)$ & $-0.05(0.20)$ & $-0.02(0.09)$ \\
\hline Offices & $0.37(0.14)^{* * *}$ & $0.24(0.14) *$ & $-0.31(0.14)^{* *}$ \\
\hline Other Structures & $0.03(0.08)$ & $0.05(0.10)$ & $0.07(0.07)$ \\
\hline Other Transportation Equipment & $0.00(0.17)$ & $-0.02(0.21)$ & $0.12(0.10)$ \\
\hline Software & $0.38(0.14)^{* * *}$ & $0.47(0.17)^{* * *}$ & $0.03(0.08)$ \\
\hline Trucks & $-0.03(0.13)$ & $-0.11(0.15)$ & $-0.01(0.09)$ \\
\hline Utility Structures & $0.05(0.08)$ & $0.15(0.11)$ & $0.10(0.09)$ \\
\hline Constant & $-0.10(0.03) * * *$ & $-0.08(0.04) * *$ & $-0.01(0.03)$ \\
\hline $\begin{array}{l}\text { Number of Observations } \\
\mathrm{R}-\mathrm{Sq}\end{array}$ & $\begin{array}{r}1472 \\
0.0393 \\
\end{array}$ & $\begin{array}{r}1274 \\
0.0395 \\
\end{array}$ & $\begin{array}{r}980 \\
0.0472 \\
\end{array}$ \\
\hline
\end{tabular}

Robust standard errors are shown in parentheses.

First-stage regressions - used to obtain productivity residuals - contain industry, state, size, and spike dummies

*** denotes significance at the $99 \%$ level

** denotes significance at the $95 \%$ level

* denotes significance at the $90 \%$ level 
Table 9 -- Production Function Regression including SGA as organizational capital proxy

\begin{tabular}{|c|c|c|c|c|c|c|c|c|}
\hline & \multicolumn{2}{|c|}{$\begin{array}{c}(1) \\
1998\end{array}$} & \multicolumn{2}{|c|}{$\begin{array}{c}(2) \\
1999\end{array}$} & \multicolumn{2}{|c|}{$\begin{array}{c}(3) \\
2000\end{array}$} & \multicolumn{2}{|c|}{$\begin{array}{c}(4) \\
2001\end{array}$} \\
\hline $\begin{array}{l}\text { Variable } \\
\text { Investment Shares: }\end{array}$ & Coef. & timate & Coef. & Estimate & Coef. & stimate & Coef. & Estimate \\
\hline Aircraft & -0.16 & $(0.15)$ & -0.11 & $(0.25)$ & -0.30 & $(0.28)$ & -0.30 & $(0.31)$ \\
\hline Autos & 0.39 & $(0.27)$ & 0.36 & $(0.29)$ & 0.41 & $(0.29)$ & 0.44 & $(0.27)$ \\
\hline Commercial Buildings & -0.05 & $(0.12)$ & -0.12 & $(0.13)$ & -0.22 & $(0.13) *$ & -0.19 & $(0.12)$ \\
\hline Communications and AV Equipment & 0.52 & $(0.26)$ ** & 0.51 & $(0.24) * *$ & 0.42 & $(0.19) * *$ & 0.38 & $(0.21)$ * \\
\hline Computers & 0.20 & $(0.09) * *$ & 0.15 & $(0.10)$ & 0.01 & $(0.11)$ & 0.02 & $(0.11)$ \\
\hline Electrical Equipment & -0.20 & $(0.24)$ & -0.23 & $(0.24)$ & -0.08 & $(0.18)$ & 0.14 & $(0.16)$ \\
\hline Fabricated Metal Products & -0.05 & $(0.11)$ & 0.04 & $(0.12)$ & 0.00 & $(0.15)$ & 0.03 & $(0.14)$ \\
\hline General Purpose Machinery & 0.06 & $(0.08)$ & 0.10 & $(0.08)$ & 0.12 & $(0.10)$ & 0.17 & $(0.11)$ \\
\hline Industrial Buildings & -0.01 & $(0.10)$ & 0.04 & $(0.10)$ & -0.04 & $(0.11)$ & -0.01 & $(0.11)$ \\
\hline Instruments & 0.02 & $(0.18)$ & -0.10 & $(0.14)$ & -0.18 & $(0.18)$ & -0.17 & $(0.18)$ \\
\hline Metalworking Machinery & 0.03 & $(0.07)$ & 0.05 & $(0.08)$ & 0.00 & $(0.08)$ & -0.02 & $(0.07)$ \\
\hline Miscellaneous Equipment & -0.04 & $(0.08)$ & -0.05 & $(0.09)$ & -0.12 & $(0.09)$ & -0.10 & $(0.08)$ \\
\hline Office Equipment & -0.06 & $(0.19)$ & -0.22 & $(0.19)$ & -0.16 & $(0.20)$ & -0.23 & $(0.21)$ \\
\hline Offices & 0.09 & $(0.15)$ & 0.18 & $(0.17)$ & 0.04 & $(0.19)$ & -0.02 & $(0.19)$ \\
\hline Other Structures & -0.13 & $(0.19)$ & 0.34 & $(0.22)$ & 0.04 & $(0.28)$ & 0.36 & $(0.24)$ \\
\hline Other Transportation Equipment & -0.08 & $(0.21)$ & -0.20 & $(0.26)$ & 0.33 & $(0.28)$ & 0.22 & $(0.23)$ \\
\hline Software & 0.33 & $(0.15) * *$ & 0.24 & $(0.17)$ & -0.01 & $(0.16)$ & 0.02 & $(0.16)$ \\
\hline Trucks & 0.38 & $(0.24)$ & 0.82 & $(0.24) * * *$ & 0.86 & $(0.31)^{* * *}$ & 0.80 & $(0.26)^{* * *}$ \\
\hline $\begin{array}{l}\text { Utility Structures } \\
\text { Other Variables: }\end{array}$ & -0.67 & $(0.51)$ & -0.27 & $(0.41)$ & -0.08 & $(0.26)$ & 0.14 & $(0.23)$ \\
\hline$\overline{\log (k)}$ & 0.27 & $(0.02) * * *$ & 0.27 & $(0.02)^{* * *}$ & 0.23 & $(0.03) * * *$ & 0.24 & $(0.02) * * *$ \\
\hline $\log (e m p)$ & 0.30 & $(0.04) * * *$ & 0.31 & $(0.04)^{* * *}$ & 0.35 & $(0.04) * * *$ & 0.29 & $(0.04) * * *$ \\
\hline $\log (\mathrm{SGA})$ & 0.38 & $(0.02)^{* * *}$ & 0.42 & $(0.02)^{* * *}$ & 0.44 & $(0.02)^{* * *}$ & 0.45 & $(0.02)$ *** \\
\hline Size Class2 & 0.00 & $(0.05)$ & 0.01 & $(0.06)$ & 0.03 & $(0.06)$ & 0.05 & $(0.06)$ \\
\hline Size Class3 & 0.06 & $(0.06)$ & 0.06 & $(0.07)$ & 0.05 & $(0.07)$ & 0.11 & $(0.07)$ * \\
\hline Size Class4 & 0.07 & $(0.08)$ & 0.06 & $(0.08)$ & 0.02 & $(0.08)$ & 0.12 & $(0.08)$ \\
\hline Size Class5 & 0.15 & $(0.11)$ & 0.04 & $(0.12)$ & -0.04 & $(0.12)$ & 0.12 & $(0.12)$ \\
\hline Spike dummy & 0.03 & $(0.03)$ & 0.02 & $(0.03)$ & -0.01 & $(0.03)$ & 0.00 & $(0.03)$ \\
\hline Constant & 2.53 & $(0.14)^{* * *}$ & 1.69 & $(0.17)^{* * *}$ & 2.56 & $(0.16)^{* * *}$ & 2.41 & $(0.17)^{* * *}$ \\
\hline $\begin{array}{l}\text { Number of Observations } \\
\text { R-Sq }\end{array}$ & $\begin{array}{r}1394 \\
0.9247\end{array}$ & & $\begin{array}{r}1264 \\
0.9294\end{array}$ & & $\begin{array}{r}1161 \\
0.9352\end{array}$ & & $\begin{array}{r}1120 \\
0.9414\end{array}$ & \\
\hline
\end{tabular}

Notes: These regressions also include 3-digit SIC industry dummies and state dummies, though due to confidentiality concerns, the coefficients on these dummies are not shown.

Robust standard errors are shown in parentheses.

*** denotes significance at the $99 \%$ level

${ }^{* *}$ denotes significance at the $95 \%$ level

* denotes significance at the $90 \%$ level 
Table 10 -- Production Function Regressions with three categories of type interactions

\begin{tabular}{|c|c|c|c|c|}
\hline & $\begin{array}{c}(1) \\
1998\end{array}$ & $\begin{array}{c}(2) \\
1999\end{array}$ & $\begin{array}{c}(3) \\
2000\end{array}$ & $\begin{array}{c}(4) \\
2001\end{array}$ \\
\hline Investment Shares: & $\underline{\text { Coef. Estimate }}$ & $\underline{\text { Coef. Estimate }}$ & $\underline{\text { Coef. Estimate }}$ & Coef. Estimate \\
\hline$\overline{\text { Aircraft }}$ & $0.08(0.15)$ & $-0.11 \quad(0.20)$ & $-0.22(0.23)$ & $-0.11(0.23)$ \\
\hline Autos & $0.50(0.32)$ & $0.44(0.41)$ & $0.50(0.39)$ & $0.60(0.37)$ \\
\hline Commercial Buildings & $-0.04 \quad(0.15)$ & $-0.12(0.16)$ & $-0.30(0.18) *$ & $-0.20(0.17)$ \\
\hline Communications and AV Equipment & $0.72(0.26)^{* * *}$ & $0.78(0.23)^{* * *}$ & $0.72(0.21)^{* * *}$ & $0.76(0.27)$ * \\
\hline Computers & $0.53(0.10)^{* * *}$ & $0.54(0.11)^{* * *}$ & $0.40(0.12)^{* * *}$ & $0.45(0.12) *$ \\
\hline Electrical Equipment & $-0.21(0.17)$ & $-0.11(0.19)$ & $-0.06(0.18)$ & $0.14(0.19)$ \\
\hline Fabricated Metal Products & $-0.06 \quad(0.13)$ & $0.00 \quad(0.15)$ & $-0.06(0.18)$ & $0.00(0.16)$ \\
\hline General Purpose Machinery & $0.15(0.10)$ & $(0.10)$ * & $0.25(0.13)$ * & $0.33(0.14)$ ** \\
\hline Industrial Buildings & $0.02(0.12)$ & $(0.12)$ & $0.04(0.14)$ & $0.10(0.14)$ \\
\hline Instruments & $0.10(0.17)$ & $(0.17)$ & $-0.07(0.20)$ & $-0.08(0.18)$ \\
\hline Metalworking Machinery & $0.02(0.08)$ & $(0.09)$ & $-0.02(0.09)$ & $-0.03(0.09)$ \\
\hline Miscellaneous Equipment & $0.10 \quad(0.12)$ & $(0.13)$ & $0.00(0.14)$ & $0.11(0.13)$ \\
\hline Office Equipment & $0.29(0.23)$ & $(0.24)$ & $0.09(0.27)$ & $0.08(0.27)$ \\
\hline Offices & $0.52(0.17)^{* * *}$ & $0.50(0.17)^{* * *}$ & $0.50(0.20) * *$ & $0.46(0.20) * *$ \\
\hline Other Structures & $-0.07(0.17)$ & $0.18(0.18)$ & $-0.19(0.25)$ & $0.28(0.23)$ \\
\hline Other Transportation Equipment & $-0.06(0.21)$ & $(0.26)$ & $-0.09(0.26)$ & $0.04(0.26)$ \\
\hline Software & $0.93(0.22)^{* * \star}$ & $0.96(0.25)^{* * *}$ & $0.77(0.22)^{* * *}$ & $0.82(0.22)^{* * *}$ \\
\hline Trucks & $-0.07(0.23)$ & $0.00 \quad(0.30)$ & $-0.14(0.27)$ & $-0.05(0.26)$ \\
\hline $\begin{array}{l}\text { Utility Structures } \\
\text { Interactions }\end{array}$ & $-0.19(0.22)$ & $-0.05 \quad(0.18)$ & $0.14 \quad(0.17)$ & $0.31(0.18)$ * \\
\hline High-tech * High-tech & $-0.52(0.27)$ * & $-0.62(0.32)$ ** & $-0.54(0.32)$ * & $-0.51(0.32)$ \\
\hline Low-tech * Low-tech & $-0.32(0.33)$ & $(0.37)$ & $-0.04(0.44)$ & $-0.25(0.42)$ \\
\hline High-tech * Low-tech & $0.42(0.20)^{* *}$ & $(0.22)^{* * *}$ & $0.45(0.24)$ * & $0.44(0.25)$ * \\
\hline$\frac{\text { Other Variables: }}{\log (\mathrm{emp})}$ & $0.52(0.04)^{* * *}$ & $0.54(0.04)^{* \star *}$ & $0.59(0.05) * * \star$ & $0.52(0.05) * * \star$ \\
\hline $\log (k)$ & $0.42(0.02)^{* * *}$ & $0.43(0.02)^{* * *}$ & $0.41(0.03)^{* * *}$ & $0.42(0.02)^{* * *}$ \\
\hline Size Class2 & $-0.05(0.06)$ & $-0.05 \quad(0.06)$ & $-0.06(0.07)$ & $-0.04(0.07)$ \\
\hline Size Class3 & $0.00(0.07)$ & $-0.01 \quad(0.07)$ & $-0.06(0.08)$ & $0.00(0.08)$ \\
\hline Size Class4 & $-0.05 \quad(0.09)$ & $-0.04 \quad(0.09)$ & $-0.11(0.09)$ & $-0.01 \quad(0.11)$ \\
\hline Size Class5 & $0.02(0.13)$ & $-0.06(0.13)$ & $-0.17(0.14)$ & $0.00(0.16)$ \\
\hline Spike dummy & $0.04 \quad(0.04)$ & $(0.04)$ & $0.03(0.04)$ & $0.04(0.04)$ \\
\hline Constant & $3.31(0.17) * * *$ & $1.86(0.24)^{* * *}$ & $3.31(0.26)^{* * *}$ & $3.11(0.22)$ ** \\
\hline $\begin{array}{l}\text { Number of Observations } \\
\text { R-Sq }\end{array}$ & $\begin{array}{r}1651 \\
0.899\end{array}$ & $\begin{array}{r}1502 \\
0.897\end{array}$ & $\begin{array}{r}1374 \\
0.898\end{array}$ & $\begin{array}{l}1335 \\
0.906\end{array}$ \\
\hline
\end{tabular}

Notes: These regressions also include 3-digit SIC industry dummies and state dummies, though due to confidentiality concerns, the coefficients on these dummies are not shown. "High-tech" consists of Computers, Communications Equipment, Software, Instruments, Electrical Equipment, Metalworking Machinery, Autos, Aerospace, and Special Industry Machinery. "Low-tech" consists of Other Office Equipment, Fabricated Metal Products, Heavy Duty Trucks, Other Transportation Equipment, General Purpose Machinery, Miscellaneous Equipment, and all Structures Types.

Robust standard errors are shown in parentheses. Coefficients on Industry and State dummies not shown.

${ }^{* * *}$ denotes significance at the $99 \%$ level

** denotes significance at the $95 \%$ level

${ }^{*}$ denotes significance at the $90 \%$ level 
Table 11 -- Interactions between Capital Types and Labor in 1998 Regression

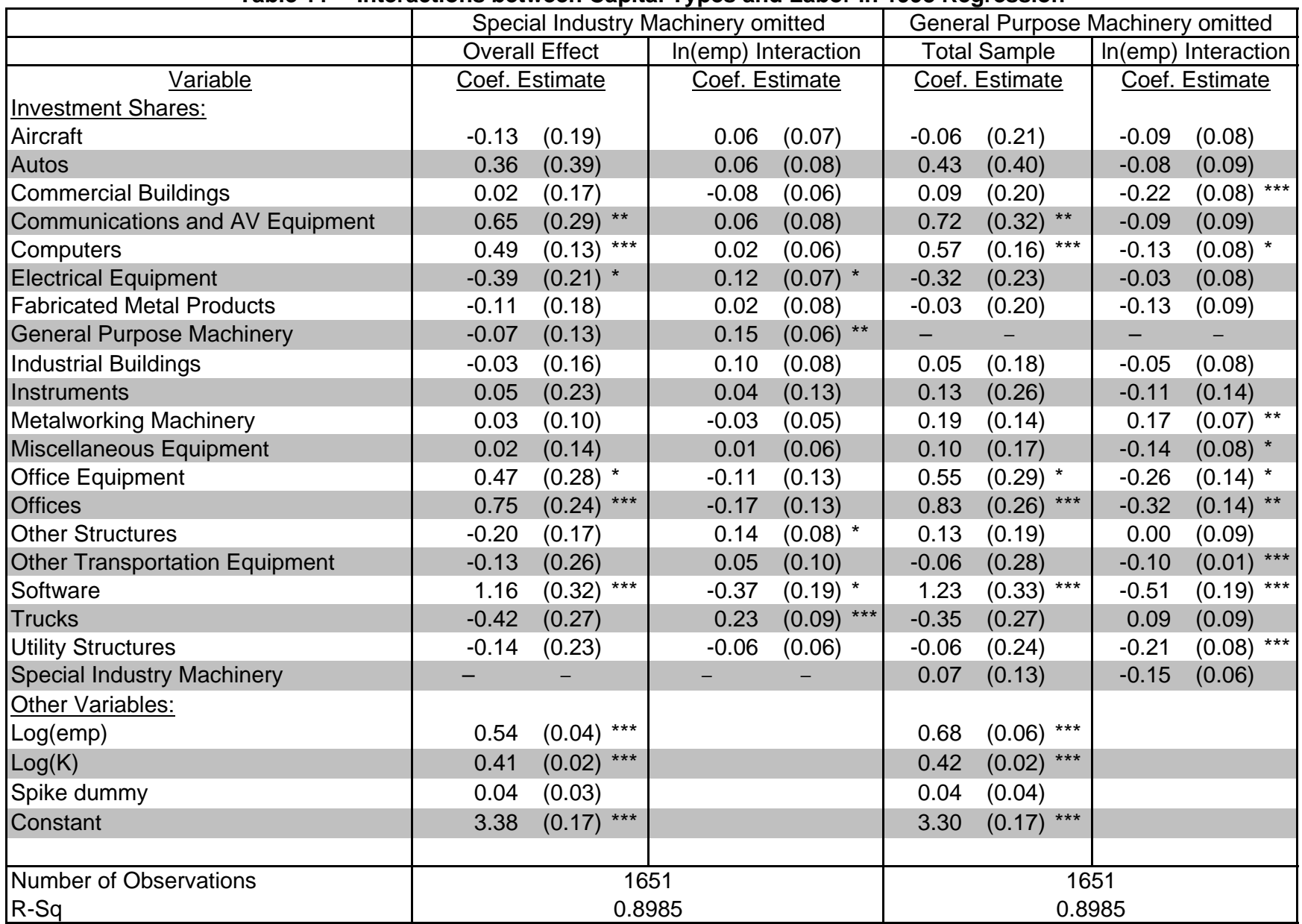

Robust standard errors are shown in parentheses. Coefficients on state and industry dummies are not shown.

${ }^{* * *}$ denotes significance at the $99 \%$ level

** denotes significance at the $95 \%$ level

${ }^{*}$ denotes significance at the $90 \%$ level 